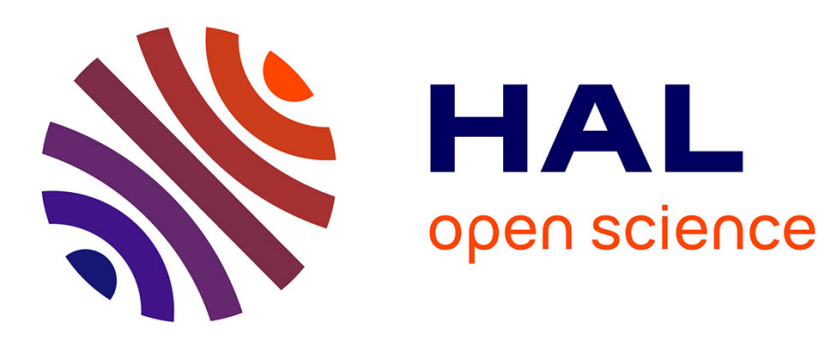

\title{
Precipitation Water Stable Isotopes in the South Tibetan Plateau: Observations and Modeling
}

Jing Gao, Valérie Masson-Delmotte, T. Yao, L. Tian, Camille Risi, G. Hoffmann

\section{- To cite this version:}

Jing Gao, Valérie Masson-Delmotte, T. Yao, L. Tian, Camille Risi, et al.. Precipitation Water Stable Isotopes in the South Tibetan Plateau: Observations and Modeling. Journal of Climate, 2011, 24 (13), pp.3161-3178. 10.1175/2010jcli3736.1 . hal-01120098

\section{HAL Id: hal-01120098 https://hal.science/hal-01120098}

Submitted on 24 Feb 2015

HAL is a multi-disciplinary open access archive for the deposit and dissemination of scientific research documents, whether they are published or not. The documents may come from teaching and research institutions in France or abroad, or from public or private research centers.
L'archive ouverte pluridisciplinaire HAL, est destinée au dépôt et à la diffusion de documents scientifiques de niveau recherche, publiés ou non, émanant des établissements d'enseignement et de recherche français ou étrangers, des laboratoires publics ou privés. 


\title{
Precipitation Water Stable Isotopes in the South Tibetan Plateau: Observations and Modeling*
}

\author{
JING GAO \\ Key Laboratory of Tibetan Environment Changes and Land Surface Processes, Institute of Tibetan Plateau Research, \\ Chinese Academy of Sciences, and Graduate University of Chinese Academy of Sciences, Beijing, China \\ V. MASSON-DELMOTTE \\ Laboratoire des Sciences du Climat et de l'Environnement, IPSL, UMR, Gif-sur-Yvette, France \\ T. YAO AND L. TIAN \\ Key Laboratory of Tibetan Environment Changes and Land Surface Processes, Institute of Tibetan Plateau Research, \\ Chinese Academy of Sciences, Beijing, China \\ C. RISI \\ LMD/IPSL, CNRS, UPMC, Paris, France \\ G. HOFFMANN \\ Laboratoire des Sciences du Climat et de l'Environnement, IPSL, UMR, Gif-sur-Yvette, France
}

(Manuscript received 19 March 2010, in final form 30 November 2010)

\begin{abstract}
Measurements of precipitation isotopic composition have been conducted on a daily basis for $1 \mathrm{yr}$ at Bomi, in the southeast Tibetan Plateau, an area affected by the interaction of the southwest monsoon, the westerlies, and Tibetan high pressure systems, as well as at Lhasa, situated west of Bomi. The measured isotope signals are analyzed both on an event basis and on a seasonal scale using available meteorological information and airmass trajectories. The processes driving daily and seasonal isotopic variability are investigated using multidecadal climate simulations forced by twentieth-century boundary conditions and conducted with two different isotopic atmospheric general circulation models [the isotopic version of the Laboratoire de Météorologie Dynamique GCM (LMDZiso) and the ECHAM4iso model]. Both models use specific nudging techniques to mimic observed atmospheric circulation fields. The models simulate a wet and cold bias on the Tibetan Plateau together with a dry bias in its southern part. A zoomed LMDZ simulation conducted with $\sim 50-\mathrm{km}$ local spatial resolution dramatically improves the simulation of isotopic compositions of precipitation on the Tibetan Plateau. Simulated water isotope fields are compared with new data and with previous observations, and regional differences in moisture origins are analyzed using back-trajectories. Here, the focus is on relationships between the water isotopes and climate variables on an event and seasonal scale and in terms of spatial and altitudinal isotopic gradients. Enhancing the spatial resolution is crucial for improving the simulation of the precipitation isotopic composition.
\end{abstract}

\footnotetext{
* Supplemental information related to this paper is available at the Journals Online Web site: http://dx.doi.org/10.1175/2010JCLI3736.s1.

Corresponding author address: Jing Gao, No. 18, 2871 Shuangqing Rd., Haidian District, Beijing 100085, China. E-mail: gaojing@itpcas.ac.cn
}

\section{Introduction}

The stable isotopes $\left({ }^{18} \mathrm{O}\right.$ and $\left.\mathrm{D}\right)$ of meteoric waters have been widely used in hydrological and climatic studies. Since the initiation of the International Atomic Energy Agency/World Meteorological Organization's (IAEA/ WMO) Global Network of Isotopes in Precipitation 
(GNIP, information online at http://www-naweb.iaea. org/napc/ih/GNIP/IHS_GNIP.html) in 1961, several decades' worth of data are available for a large number of stations, which, combined with theoretical one-dimensional (Ciais and Jouzel 1994) and three-dimensional models (Jouzel et al. 1994), provide improved our understanding of the mechanisms of stable isotopic fractionation in natural processes (Dansgaard 1964; Jouzel and Merlivat 1984; Jouzel et al. 1997). In the late 1980s, large gaps remained in the spatial coverage of GNIP stations, in particular on the Tibetan Plateau. This area acts as a "water tower" for surrounding lowlands; therefore, determining the controls on the isotopic composition of precipitation is crucial to understanding the origin of moisture and has implications for hydrological, tree-ring, and ice-core paleoclimate studies (Thompson et al. 2000; Tian et al. 2003; Yao et al. 2008).

There was thus an urgent need for improvements in our monitoring and understanding of modern precipitation isotopic composition over the Tibetan Plateau region. Since the 1990s, a network of about a dozen isotopic sampling sites has been established on the Tibetan Plateau, and has routinely operated on a monthly time step (Tian et al. 2003). These observations have revealed the regional complexity of geographical and climatic factors driving precipitation isotopic composition (Tian et al. 2003, 2007; Zhang et al. 2005; Kurita and Yamada 2008; Liu et al. 2008; Yu et al. 2008 ) and the imprint of airmass origins on this composition (Araguas-Araguas et al. 1998; Aizen et al. 2006; Tian et al. 2007).

In parallel with the development of monitoring networks, water stable isotopes have been implemented in atmospheric general circulation models (AGCMs) since the early 1980s (Jouzel et al. 1987; Hoffmann and Heimann 1997; Hoffmann et al. 1998; Mathieu et al. 2002; Noone and Simmonds 2002; Vuille et al. 2005; Schmidt et al. 2007; Lee et al. 2007; Yoshimura et al. 2008; Tindall et al. 2009; Risi et al. 2010), significantly improving our understanding of the processes driving precipitation isotopic composition (Joussaume et al. 1984). Modeling water stable isotopes provides an independent evaluation of the modeled water cycle and climate. Moreover, the consistent physical framework of the model enables analysis of the climatic controls on the spatial and temporal precipitation isotopic compositions, on global or regional scales. Based on our present-day capabilities, isotopic AGCMs have also been used to explore the temporal stability of the isotope-climate relationship under varying paleoclimate boundary conditions (e.g., glacial climate, or changing orbital parameters) (Jouzel et al. 2000; Hoffmann et al. 2000; LeGrande and Schmidt 2009). While many of these studies focused on the polar ice caps and the interpretation of polar deep-drilling sites, they have revealed the importance of atmospheric circulation changes in the local relationships between changes in precipitation isotopic composition and climate, including the Asian area (e.g. LeGrande and Schmidt 2009).

For the Tibetan Plateau, comparisons between isotopic AGCMs and data remain a challenge. Earlier studies (Hoffmann et al. 1998; Yoshimura et al. 2003; Vuille et al. 2005) have shown that some models can capture the major observed spatial patterns, but perform better for shortterm (daily or several days) isotope variability than on seasonal or interannual time scales. The challenge is first due to the difficulty in realistically capturing the basic features of the atmospheric circulation and precipitation in the area, including the correct airmass advection and local recycling patterns (Kurita and Yamada 2008). Recent studies have shown remarkable improvements in the realism of simulated precipitation (Shi et al. 2008; Nguyen and McGregor 2009). Model-data mismatches can be linked with the complex Tibetan Plateau topography (Chow and Chan 2009). Due to the current spatial resolution of AGCMs, they cannot capture the impacts of subgrid topography on regional circulation. The second challenge for Tibetan Plateau model-data comparisons is the lack of empirical observations on the Tibetan Plateau, which limits our knowledge of spatial and temporal precipitation isotopic composition gradients and, in particular, of the submonthly variability. The monthly mean isotopic composition is indeed produced by the juxtaposition of individual precipitation events. Filling observational gaps is therefore essential to better understand the processes at play and to evaluate the water cycle simulated by the atmospheric models.

The first goal of this paper is to reveal the daily and seasonal characteristics of isotopic compositions in precipitation and understand the links between isotopic compositions in precipitation and the moisture trajectory path to the south of the Tibetan Plateau, in relationship with monsoon dynamics (Sengupta and Sarkar 2006). For this purpose, we present new observations of precipitation isotopic composition from a $\sim 1$-yr (October 2007-November 2008) monitoring experiment conducted on an event basis at two locations, Bomi and Lhasa, both in the south area of the Tibetan Plateau. We analyze their relationships with local meteorological parameters. Then these relationships were confirmed by simulated moisture trajectory from the isotopic version of the Laboratoire de Météorologie Dynamique GCM (LMDZiso).

The second goal of this paper is to evaluate the model performance of stable isotopes in precipitation on different time scales along the southern Tibetan Plateau. We use three nudged simulations run with two isotopic AGCMs (LMDZiso at two different spatial resolutions and ECHAM4iso) to analyze the distribution and processes 


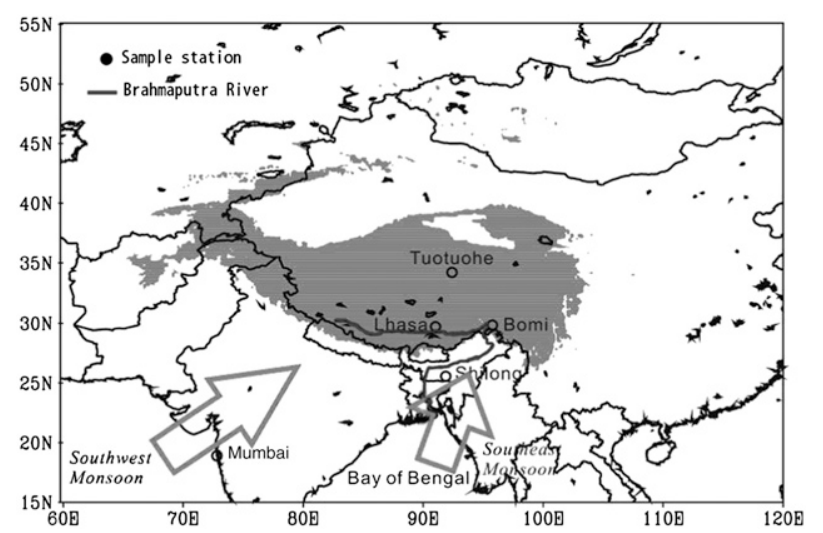

FIG. 1. Location of the study area and sites of interest. Open circles indicate the locations of the five precipitation sampling sites providing temperature and precipitation data. This paper uses unpublished data from Bomi and Lhasa together with available data from Lhasa, Mumbai, Shilong, and Tuotuohe. Arrows show the general patterns of summer moisture transport that affect the seasonal isotopic variations of precipitation in the study area. The gray shading is a mask of elevations $>3000 \mathrm{~m}$. In this paper, we have performed new measurements of $\delta \mathrm{D}$ on Tuotuohe monthly mean precipitation samples in order to depict its d-excess seasonal cycle (see section 4).

controlling south Tibetan precipitation isotopic composition. The seasonal, annual, spatial, and altitudinal variations of the precipitation isotopic composition simulated by both models are compared with the monthly observations from three Tibetan stations (Bomi, Lhasa, and Tuotuohe, China) and two nearby stations (Mumbai and Shilong, India) influenced by the Asian monsoon.

In section 2, we describe the study area, the observational data used here, and the AGCM models enabled with water stable isotopes. In section 3 , we discuss the relationships between the observed stable isotopic compositions and the meteorological data. In section 4, we compare observations with simulations from LMDZiso and ECHAMiso.

\section{Material and methods}

\section{a. Study area}

Located on the southeastern margin of the Tibetan Plateau, at the junction of the Nyainqentanglha and Himalaya Mountains, the Bomi area $\left(29^{\circ} 21^{\prime}-30^{\circ} 40^{\prime} \mathrm{N}\right.$, $94^{\circ} 00^{\prime}-96^{\circ} 30^{\prime} \mathrm{E}$ ) is a crucial region for studying moisture transport processes and the interaction of major circulation systems (southwest monsoon, westerly flow, and the Tibetan high pressure system; see Fig. 1).

Moving along the Brahmaputra River, the southern moisture flow reaches this area with the onset of the Indian monsoon, resulting in abundant rainfall. At Bomi, located in the valley of the Parlang Zangbo River $\left(29^{\circ} 50^{\prime} \mathrm{N}\right.$, $95^{\circ} 47^{\prime} \mathrm{E}, 2730 \mathrm{~m} \mathrm{MSL}$ ), meteorological data show that the annual mean precipitation is $\sim 835 \mathrm{~mm}$ (from 1961 to 2003) with evaporation reaching $\sim 700 \mathrm{~mm}$ (from 1980 to 2003). Monthly mean precipitation amounts are higher than $50 \mathrm{~mm}$ from March to October and usually peak in June. The annual mean relative humidity is about $71 \%$, reaching up to $80 \%$ in September. The annual mean temperature is $8.6^{\circ} \mathrm{C}$, ranging from $0^{\circ} \mathrm{C}$ in January to $16.5^{\circ} \mathrm{C}$ in July (Fig. 2a). During our sampling year (from October 2007 to November 2008), the spring and summer (March-September) precipitation amount accounts for $\sim 80 \%$ of the annual rainfall, similar to the long-term average precipitation percentage at Bomi recorded at the meteorological station. The average temperature $\left(9.9^{\circ} \mathrm{C}\right)$ and relative humidity $(72 \%)$ are also close to the longterm averages. We can therefore consider that this single year of precipitation isotopic composition observations represents a "normal monsoon" year.

Lhasa is located in a vast valley along the Brahmaputra River, to the west of Bomi by $570 \mathrm{~km}$. The annual mean precipitation amount at the Lhasa meteorological station $\left(29^{\circ} 42^{\prime} \mathrm{N}, 9^{\circ} 08^{\prime} \mathrm{E}, 3650 \mathrm{~m} \mathrm{MSL}\right)$ is $\sim 620 \mathrm{~mm}$, and the area is dominated by monsoon precipitation, with about $85 \%$ of the total annual precipitation occurring as rainfall from May to September. The annual mean temperature is $7.5^{\circ} \mathrm{C}$ and the annual mean relative humidity is about $47 \%$, showing that Lhasa is drier than Bomi outside of July-August (Fig. 2b). The interannual variabilities in monthly temperature and relative humidity are higher at Lhasa than are those at Bomi; while Bomi shows a larger variability of annual precipitation. During our sampling year (October 2007-November 2008), the rainfall from May to September accounts for $90 \%$ of the total annual precipitation; similar to the long-term average percentage of precipitation occurring during the monsoon period at Lhasa. At Lhasa, the precipitation isotopic composition has been monitored on an event basis since the 1990s (Tian et al. 2003). The annual weighted mean $\delta^{18} \mathrm{O}$ in precipitation calculated from our event-based sampling (see next section) $(-16.9 \%$ ) is close to the multiyear weighted mean values $(-17.4 \%)$. Thus, our observation year is representative of a normal monsoon year and the isotopic composition of precipitation from Lhasa and Bomi is comparable to comparisons with other long-term datasets. These results will be discussed in section 3 .

Here, we also refer to monthly mean observations available from different precipitation collection stations on and around the Tibetan Plateau: two stations in the IAEA's GNIP network (Mumbai and Shilong) (data available from 1961 to 1978, downloaded from the Web site http:// www-naweb.iaea.org/napc/ih/GNIP/IHS_GNIP.html) and Lhasa and Tuotuohe, meteorological stations (our observations; data available from 1996 to 1999; see Fig. 1). 

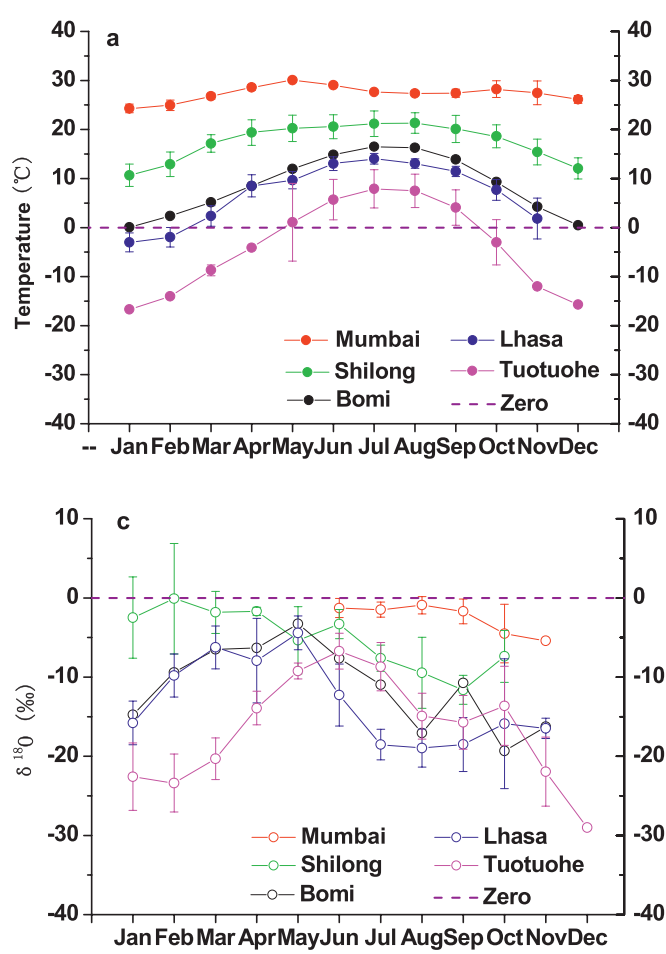

Figure 2 shows the mean seasonal variations of meteorological conditions and observed monthly mean $\delta^{18} \mathrm{O}$ in precipitation at these five stations. Mumbai (10 m MSL) is our southernmost site, with an annual mean temperature of $27.1^{\circ} \mathrm{C}$ and an annual precipitation amount of $\sim 1985 \mathrm{~mm}$, which is mostly (90\%) provided by wet season precipitation (June-September). The climate at Shilong, located northward and at higher altitude (1598 m MSL), is colder (annual mean temperature of $14.7^{\circ} \mathrm{C}$ ) and is also controlled by the summer monsoon, with a mean annual precipitation amount of $\sim 2155 \mathrm{~mm}$. As previously explained, Bomi and Lhasa are located in the valley near the Brahmaputra where monsoon moisture is transported toward the southern Tibetan Plateau (Lin and Wu 1990). Tuotuohe with the highest altitude $(4533 \mathrm{~m})$ is our northernmost, coldest (annual mean temperature of $\left.-3.8^{\circ} \mathrm{C}\right)$, and driest $\left(\sim 260 \mathrm{~mm} \mathrm{yr}^{-1}\right)$ site, as it is outside of the monsoon influence and is under the influence of continental air masses. The observed monthly mean weighted $\delta^{18} \mathrm{O}$ in precipitation decreases from south to north, except for at Tuotuohe (Fig. 2c). In the southern Tibetan Plateau, the amount effect dominates the variation of precipitation $\delta^{18} \mathrm{O}$ and the heavy isotopes undergo a gradual depletion along the northward monsoon transport. In the northern Tibetan Plateau, a different moisture origin is found and the variations in precipitation $\delta^{18} \mathrm{O}$ are controlled by temperature (Tian et al. 2003, 2007). These monthly mean records

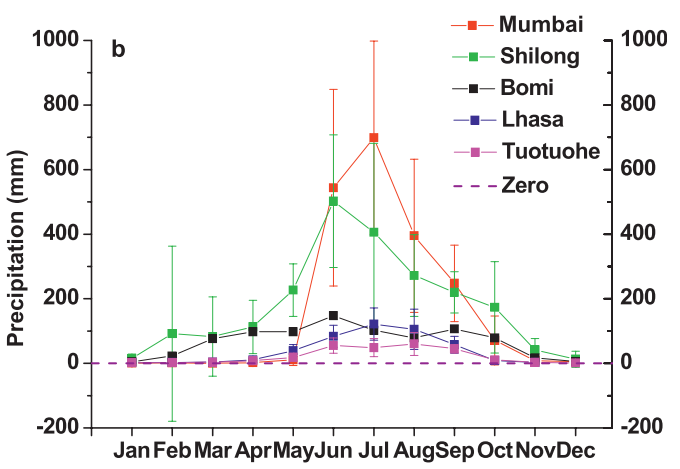

FIG. 2. Mean seasonal cycle of meteorological conditions at five stations (red represents Mumbai, green represents Shilong, black represents Bomi, blue represents Lhasa, and magenta represents Tuotuohe): (a) monthly mean temperature $\left({ }^{\circ} \mathrm{C}\right)$, (b) precipitation amount $(\mathrm{mm}$ month ${ }^{-1}$ ), and (c) observed $\delta^{18} \mathrm{O}(\%)$ in precipitation. Vertical error bars display the interannual monthly standard deviations. Purple lines are reference horizontal lines. The monthly mean data are available at Mumbai from 1961 to 1976, at Shilong from 1966 to 1978, and at Lhasa and Tuotuohe from 1996 to 1999.

will be discussed in detail in section 4 for comparison with isotopic simulations.

\section{b. Precipitation sampling and data acquirement}

Precipitation samples were collected on an event basis from October 2007 to November 2008 at the Bomi and Lhasa meteorological stations. Rainfall samples were immediately sealed in plastic bottles to prevent evaporation. Solid precipitation samples were collected and melted at room temperature, and then preserved as rainfall samples. All of the samples were stored frozen until analysis.

The isotopic composition of the 113 precipitation samples at Bomi was measured at the Laboratoire des Sciences du Climat et de l'Environnement, France. The $\delta^{18} \mathrm{O}$ amounts were measured by equilibration on a MAT-252 mass spectrometer, with an analytical precision of $0.05 \%$, and $\delta \mathrm{D}$ was measured by reduction on uranium, with an analytical precision of $0.5 \%$. The $\delta^{18} \mathrm{O}$ measurements of the 90 precipitation samples at Lhasa were performed with a MAT-253 mass spectrometer with GasBench-II (Thermo Scientific, Waltham Massachusetts) and the $\delta \mathrm{D}$ of 156 precipitation samples were measured by inductively coupled plasma mass spectrometry (ICP-MS; X-7 series, Thermo Scientific) at the Key Laboratory of the Chinese Academy of Sciences (CAS) for Tibetan Environment and Land Surface Processes, Institute of Tibetan Plateau Research, with a precision of $0.05 \%$ for $\delta^{18} \mathrm{O}$ and $0.5 \%$ for 
TABLE 1. Model resolutions and basic outputs information.

\begin{tabular}{lllll}
\hline \multicolumn{1}{c}{ Model } & \multicolumn{1}{c}{ Simulation date } & Data type & \multicolumn{1}{c}{ Data No. } & \multicolumn{1}{c}{ Model resolution } \\
\hline Standard LMDZ & 1 Jan 1979-31 Dec 2007 & Daily & $10592 \times 5$ & $2.5^{\circ}$ lat $\times 3.75^{\circ}$ lon, 19 vertical layers \\
Zoomed LMDZ & 1 Jan 2005-31 Dec 2007 & Daily & $1095 \times 5$ & $50-60 \mathrm{~km}, 19$ vertical layers \\
ECHAM & Jan 1970-Dec 2001 & Monthly & $384 \times 5$ & $2.8^{\circ}$ lat $\times 2.8^{\circ}$ lon, 19 vertical layers \\
\hline
\end{tabular}

$\delta \mathrm{D}$. All of the measured results were calibrated with respect to Vienna standard mean ocean water (VSMOW). Interlaboratory $\delta^{18} \mathrm{O}$ comparisons were conducted with 53 samples and demonstrate the lack of systematic biases (the average of the difference is $0.02 \%$ and the standard deviation is $0.07 \%$ ), making possible the comparison of the spatial and temporal variations of $\delta^{18} \mathrm{O}$ in precipitation at Bomi and Lhasa.

The air temperatures and precipitation amounts were recorded for each precipitation events at both stations, through the average of the observed temperature before and after the precipitation event, and through the total precipitation amount for each event. Monthly meteorological data are also available from 1961 to 2003 (see section 2a).

\section{c. AGCM simulations}

Two isotopic GCMs (LMDZiso and ECHAMiso) are used in this paper to evaluate the performance of simulations and explore processes that control the isotopic composition of precipitation in India and the Tibetan Plateau.

LMDZ, developed at the Laboratoire de Météorologie Dynamique (LMD), is the atmospheric component of the L'Institut Pierre-Simon Laplace (IPSL) model. The model resolution is shown in Table 1 . The dynamical equations are discretized on a latitude-longitude grid. Water in its vapor and condensed forms is advected by the Van Leer advection scheme (Van Leer 1977), which is a monotonic second-order finite-volume scheme. The physical parameterization scheme is described in detail in Hourdin et al. (2006). It includes the Emanuel convective parameterization (Emanuel 1991; Emanuel and ZivkovicRothman 1999) coupled to the (Bony and Emanuel 2001) cloud scheme. Risi et al. (2010) describe in detail the implementation of water stable isotopes in LMDZiso and the performances of the model for present and past climates. The representation of isotopic processes in the convection scheme is described in Bony et al. (2008). In this paper, we use three different simulations conducted with LMDZiso. The first is a climatological simulation run from 1979 to 2007 using the Atmospheric Model Intercomparison Project (AMIP) protocol (Gates 1992). In this simulation monthly interannually varying SSTs and sea ice, as well as a fixed $\mathrm{CO}_{2}$ value (348 ppm), are prescribed (Risi et al. 2010). The second run is a "nudged" simulation. Using the same boundary conditions as in the first run, the horizontal wind fields are nudged to the European Centre for Medium-Range Weather Forecasts (ECMWF) reanalysis results (Uppala et al. 2005). To do so, the simulated winds are relaxed in each grid box and at all levels toward the reanalyzed winds with a relaxation time of $1 \mathrm{~h}$ (Coindreau et al. 2007; Xin et al. 2008; Risi et al. 2010). In this case, the simulated large-scale wind field is consistent with the observations, making possible the comparison of simulated and observed daily or monthly meteorological conditions and precipitation isotopic compositions. The third run is an additional nudged simulation, as in the second, was performed using the zoom functionality of the LMDZ model. The grid was stretched so that the horizontal resolution was in the range of $50-60 \mathrm{~km}$ in a domain extending between $0^{\circ}$ and $55^{\circ} \mathrm{N}$ and $60^{\circ}$ and $130^{\circ} \mathrm{E}$. This domain is larger than that in Fig. 1, so that each of our sites of interest is far enough from the zoom borders. This additional zoomed simulation was run over 3 yr (200507) to test the impact of spatial resolution on LMDZ outputs (see section 4). As in the second run, horizontal winds were nudged to the ECMWF reanalyses with relaxation times of 1 and $4 \mathrm{~h}$ outside and inside the zoom, respectively.

Here, we compare LMDZiso results with the results of another AGCM previously used for the monsoon area (Hoffmann and Heimann 1997). The ECHAM model has 19 vertical layers, from surface pressure up to a pressure level of $30 \mathrm{hPa}$, with a horizontal resolution of $2.8^{\circ} \times 2.8^{\circ}$ (time step of $24 \mathrm{~min}$; see Table 1). The model's specific humidity and optional tracers are transported using a semiLagrangian advection scheme (Rasch and Williamson 1990). This model is documented in detail in Roeckner et al. (1996). The water isotope physics was implemented in a way similar to that in the Goddard Institute for Space Studies (GISS) AGCM (Jouzel et al. 1987), which is described in Hoffmann et al. (1998). It should be pointed out that there are four main differences between LMDZiso and ECHAMiso. First, LMDZ is a grid-point model whereas ECHAM is a spectral model, though it is combined with a semi-Lagrangian transport. Second, the ECHAM has a higher global horizontal resolution than LMDZ in the standard resolution, but a coarser one than LMDZ in the zoomed configuration. Third, LMDZiso explicitly calculates the evolution of raindrops composition as they evaporate into, and re-equilibrate with, the 
surrounding vapor following Stewart (1975), as detailed in Bony et al. (2008). In contrast, ECHAM prescribes a constant percentage of raindrops that re-equilibrates depending on two cloud types. Fourth, the evolution of both the rain and vapor compositions throughout the evaporation process is considered in LMDZiso, contrary to ECHAM (as detailed in Bony et al. 2008).

As for LMDZiso, we use here two different simulations: 1) A "free" 1970-2001 ECHAM run using monthly SST, sea ice, and greenhouse gas concentration datasets (Hurrell and Trenberth 1999) and 2) a nudged simulation where the 3D horizontal winds are also nudged toward the results of the 40-yr ECMWF Re-Analysis (ERA40; Uppala et al. 2005).

\section{Observed characteristics of stable isotopes in precipitation in the south Tibetan Plateau}

In this section, we first show the observed isotopic composition of precipitation at Bomi from 2007 to 2008 and its relationships with local meteorological data. We then compare the temporal distributions and seasonal cycles of the observations at Bomi and Lhasa to explore the different moisture origins.

\section{a. Isotopic compositions of precipitation at Bomi and links with local weather variables}

Figure 3 presents the temporal variations in the relative humidity, air temperature, precipitation amount, and precipitation $\delta^{18} \mathrm{O}$ of individual precipitation events collected at Bomi from October 2007 to November 2008 (see methods in section $2 \mathrm{a}$ ). The $\delta^{18} \mathrm{O}$ values show significant seasonality and, at the event basis, some links with local weather parameters. During the dry winter, the most depleted $\delta^{18} \mathrm{O}$ values occur within the largest storm precipitation events. From November 2007 to May $2008, \delta^{18} \mathrm{O}$ values vary between $5.5 \%$ and $-22.8 \%$ and are positively correlated with temperature $(R=$ $0.58, n=41$ ), in agreement with the isotopic temperature effect (Dansgaard 1964). From June to October, $\delta^{18} \mathrm{O}$ is progressively depleted, varying from $-0.5 \%$ to $-29.1 \%$. During this summer-autumn period, the lowest $\delta^{18} \mathrm{O}$ values correspond to the highest precipitation amounts, with a correlation coefficient of $-0.56(n=72)$ between $\delta^{18} \mathrm{O}$ and precipitation amount. Notably, in March and April, marked by $200 \mathrm{~mm}$ of total precipitation, $\delta^{18} \mathrm{O}$ values show a positive correlation with temperature $(R=0.47, n=23)$, a negative correlation with relative humidity $(R=-0.56, n=23)$, and no correlation with precipitation amount. In October, $\delta^{18} \mathrm{O}$ values are lowest and show no linear correlation with temperature or relative humidity but the strongest inverse correlation with precipitation $(R=-0.72, n=14)$.
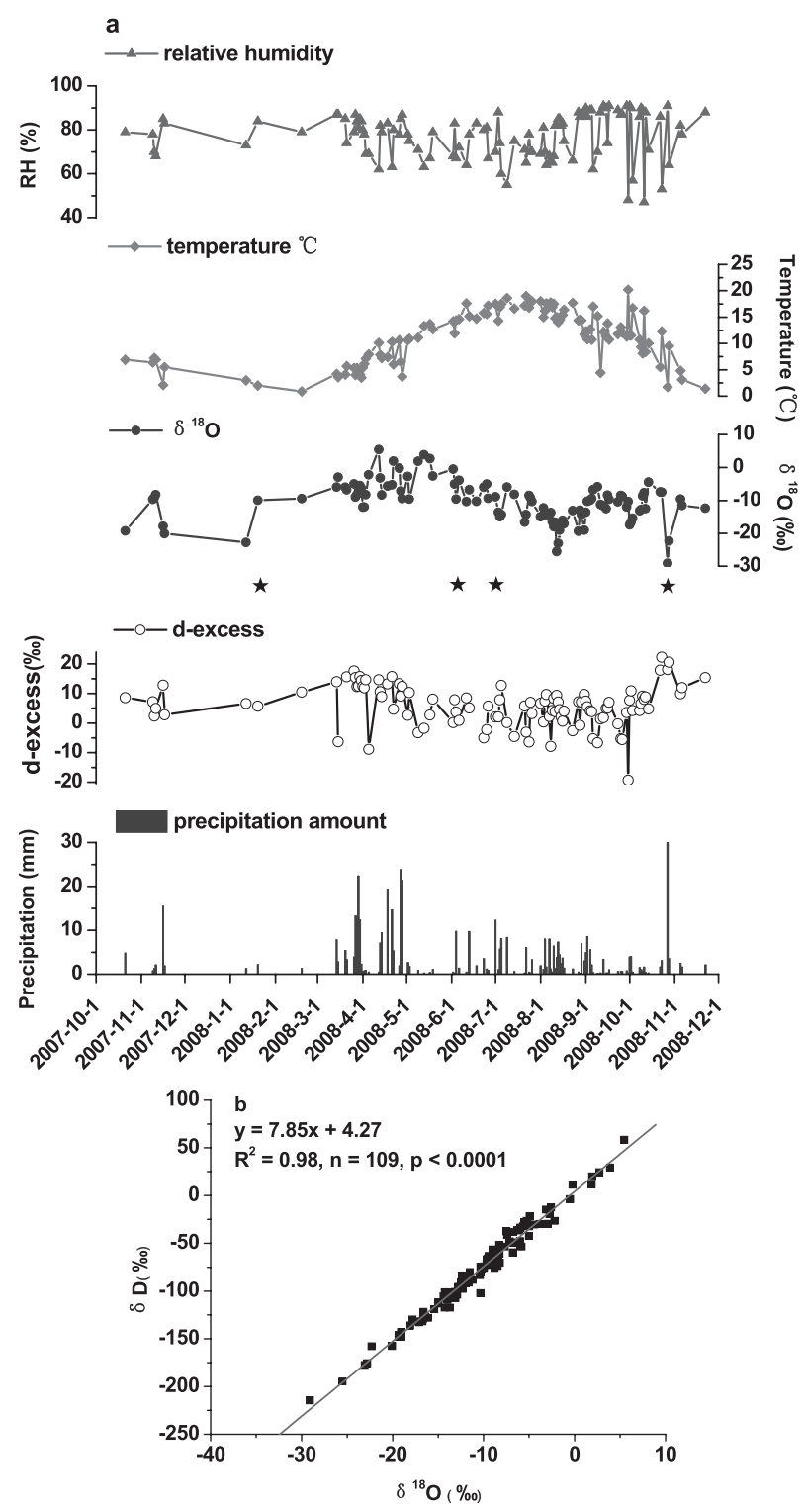

FIG. 3. (a) (top to bottom) Observed event-based RH, temperature, $\delta^{18} \mathrm{O}$ in precipitation, $\mathrm{d}$ excess, and precipitation at Bomi, from October 2007 to December 2008. The black stars show the days for which back-trajectories are shown in Fig. S1 of the supplemental material, from left to right: 12 Jan, 3 Jun, 1 Jul, and 27 Oct 2008. (b) The $\delta$ D vs $\delta^{18} \mathrm{O}$ plot for all precipitation samples defining the LMWL at Bomi.

All of these correlation coefficients are significant at a level exceeding $99 \%$ and demonstrate that, at the event basis, different meteorological factors affect the variations in Bomi precipitation $\delta^{18} \mathrm{O}$ in different seasons.

Additional deuterium measurements enable discussion of the local meteoric water line and the deuterium excess variability. The local meteoric water line (LMWL) at Bomi is calculated as $\delta \mathrm{D}=7.85 \delta^{18} \mathrm{O}+4.27\left(R^{2}=0.98\right)$ (Fig. 3b). The observed slope at Bomi is close to the 


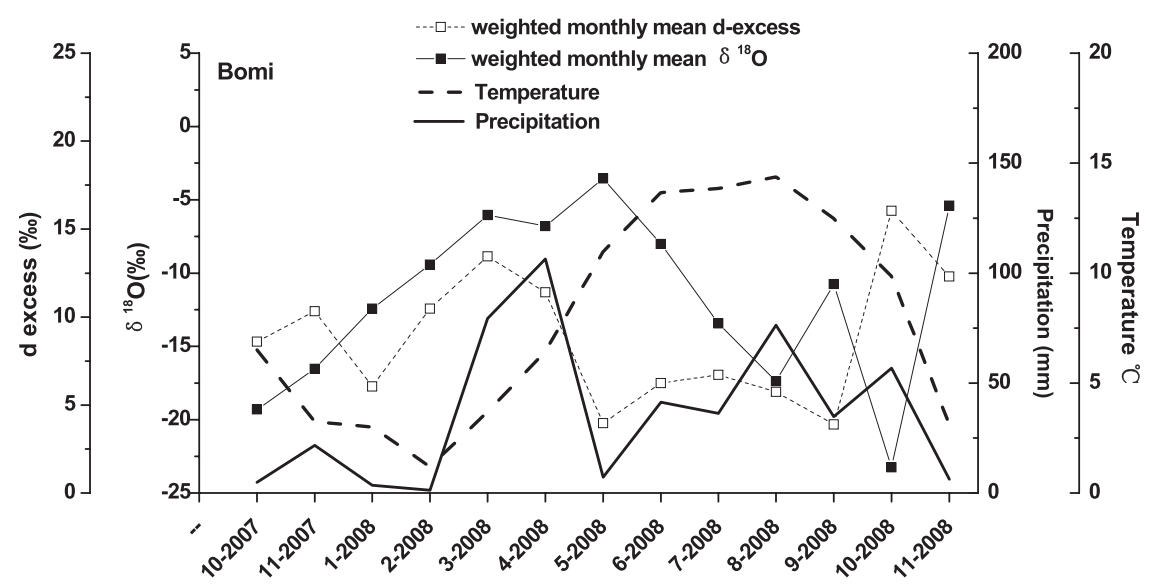

FIG. 4. Monthly precipitation-weighted $\delta^{18} \mathrm{O}$ and d excess observed at Bomi along with the monthly precipitation amount and monthly mean temperature.

slope of 8 for the global meteoric water line (Yurtsever and Gat 1981) and suggests a limited impact of nonequilibrium processes on precipitation. This value is also very close to the slope of LMWL at Lhasa (7.9), as well as other observed values reported by Tian et al. (2001). The intercept of 4.27 is rather low, compared to values of 10 in the global precipitation data, $\sim 8.0$ at Mumbai and Shilong (Gupta et al. 2005), and 6.2 in LMWL at Lhasa (Tian et al. 2001). This low intercept reflects high relative humidity at Bomi's moisture source (Clark and Fritz 1997).

The d excess $\left(\mathrm{d}=\delta \mathrm{D}-8 \delta^{18} \mathrm{O}\right.$; Dansgaard 1964) of precipitation events varies between $-8.9 \%$ to $22.3 \%$. The annual precipitation weighted mean $\mathrm{d}$ excess $(9.8 \%$ ) is close to the $d$ excess of precipitation at Kolkata (Sengupta and Sarkar 2006). For the whole dataset, $\mathrm{d}$ excess is negatively correlated with Bomi temperature, with a correlation coefficient of -0.51 (slope $=-0.75 \%{ }^{\circ} \mathrm{C}^{-1}, n=109, p<0.0001$ ) and positively correlated with the precipitation amount $(\mathrm{R}=0.42$, slope $\left.=0.50 \% \mathrm{~mm}^{-1}, n=109, p<0.0001\right)$. There is no significant correlation between the $d$ excess of events and temperature, precipitation amount, and relative humidity in winter, spring, and autumn. In summer, the d excess of events shows a positive relationship with precipitation amount $\left(R=0.49\right.$, slope $\left.=0.77 \% \mathrm{~mm}^{-1}, p<0.0001\right)$ and does not show any correlation with local relative humidity. Seasonal shifts in deuterium excess reflect the inflow of monsoon moisture (Fig. S1 in the supplemental material), with May-September levels below $10 \%$.

The seasonal variations appear more clearly from monthly precipitation weighted data (Fig. 4). The monthly $\delta^{18} \mathrm{O}$ increases with temperature from February to May, and shows an inverse correlation with precipitation amount from June to October. Apparently, the links between weather and $\delta^{18} \mathrm{O}$ are therefore consistent from the event base to the monthly scale at Bomi: precipitation $\delta^{18} \mathrm{O}$ appears to be mostly driven by changes in the local precipitation amount during the monsoon season and by local temperature changes during the rest of the year.

Since $\mathrm{d}$ excess is affected by the relative humidity, temperature, and wind speed during primary evaporation (Merlivat and Jouzel 1979), it is expected to reflect different moisture levels during the monsoon season and nonmonsoon seasons in this region (Tian et al. 2007; $\mathrm{Xu}$ et al. 2009). It has poor correlation with latitude (Rozanski et al. 1992). Starting from high winter-spring values $(\sim 11 \%)$, the monthly precipitation-weighted d excess abruptly decreases in May to reach a low $\sim 5 \%$ level that persists until September, close to the d excess of surface water near the Bay of Bengal coast in eastern India (Gupta et al. 2005). After September, d excess increases while there is no clear shift in $\delta^{18} \mathrm{O}$.

The seasonal cycle of the Bomi precipitation isotopic composition can be interpreted as resulting from different air masses: during late autumn-spring, an inflow of continental (the westerlies and local convection; see Fig. S2 in the supplemental material) air masses is marked by a temperature control of $\delta^{18} \mathrm{O}$ and high d-excess values; during summer and early autumn, the monsoon flow is marked by a precipitation effect of $\delta^{18} \mathrm{O}$, a progressive depletion of $\delta^{18} \mathrm{O}$, and low d-excess values. In May and September-October, the isotopic data suggest a simultaneous occurrence of continental and monsoon moisture transport systems.

\section{b. Comparison of precipitation $\delta^{18} \mathrm{O}$ at Bomi and Lhasa}

The main monsoonal moisture flow is transported along the Brahmaputra River toward the southern Tibetan Plateau (Gao et al. 1985; Lin and Wu 1990; Tian et al. 2003, 2007). Here, we compare the precipitation $\delta^{18} \mathrm{O}$ 
TABLE 2. Precipitation sampling at Bomi and Lhasa during 2007-08.

\begin{tabular}{lcccccc}
\hline \hline Stations & \multicolumn{1}{c}{ Obs periods } & Alt $(\mathrm{m})$ & $\begin{array}{c}\text { No. of } \\
\text { samples }\end{array}$ & $\begin{array}{c}\text { Total precipitation } \\
(\mathrm{mm})\end{array}$ & $\begin{array}{c}\text { No. of summer } \\
\text { events }\end{array}$ & $\begin{array}{c}\text { Precipitation amount in } \\
\text { summer (mm) }\end{array}$ \\
\hline Bomi & 21 Oct 2007 to 22 Nov 2008 & 2730 & 113 & 652.5 & 57 & 292.6 \\
Lhasa & 9 Oct 2007 to 4 Nov 2008 & 3658 & 90 & 524 & 62 & 427.3 \\
\hline
\end{tabular}

sampled in parallel at these two locations on an event basis to estimate the difference in moisture transport.

At each station, the number of precipitation samples (Table 2) depends on the precipitation frequency and the seasonal precipitation distribution. At Lhasa, precipitation events primarily take place in summer (JuneSeptember, JJAS), while Bomi precipitation events are more evenly distributed, mostly from March to October. Although Lhasa and Bomi are located at the same latitude and within $570-\mathrm{km}$ distance, Lhasa received $128.5 \mathrm{~mm}$ less precipitation during our sampling period (Table 2, Fig. 5), consistent with the climatological averages (see section 2a). Two main reasons can be invoked to explain this difference: 1) earlier onset and later retreat of monsoon flow at Bomi than at Lhasa and 2) stronger continental recycling and convection near Bomi (with higher relative humidity), providing larger precipitation amounts.

At both stations, the seasonal distribution of precipitation $\delta^{18} \mathrm{O}$ is characterized by peak $\delta^{18} \mathrm{O}$ values in spring (March-May, MAM) and minimum summer $\delta^{18} \mathrm{O}$ values (JJAS) (Fig. 5a). During our observation period, the summer precipitation amount is more than $100 \mathrm{~mm}$ higher at Lhasa compared to Bomi, with $57 \%$ of the total summer precipitation amounts at Lhasa and $68 \%$ at Bomi occurring on the same days. This suggests the influence of common large-scale processes. During summer, $\delta^{18} \mathrm{O}$ values are systematically $5.3 \%$ more depleted at Lhasa than those of simultaneous precipitation events sampled at Bomi. This could be linked to the orographic uplift of monsoon flow, resulting in deeper convection at Lhasa, located about $1000 \mathrm{~m}$ higher than Bomi.

Figure $5 \mathrm{~b}$ displays the relationships between summer precipitation $\delta^{18} \mathrm{O}$ and precipitation amount at the monthly scale and at the event basis (Fig. 5c). On a monthly scale, the isotopic depletions at Bomi and Lhasa ( $-9 \%$ and $-8 \%$ from June to August) are comparable despite a factor of 2 in the precipitation amounts at these 2 locations; being much higher at Lhasa. There is a general inverse correlation between monthly mean $\delta^{18} \mathrm{O}$ and precipitation amount at Lhasa. In particular, the difference in the relationship between precipitation $\delta^{18} \mathrm{O}$ and precipitation amount at these two stations in June and July may indicate more complicated moisture origins at Bomi. At the event scale, the "amount effect" is much stronger at Lhasa than at Bomi, both in terms of correlation coefficient and in terms of the $\delta^{18} \mathrm{O}$-precipitation slope: precipitation $\delta^{18} \mathrm{O}$ does not show an obvious correlation with daily temperature during our observation period at Lhasa. In the summer (JJAS), the precipitation $\delta^{18} \mathrm{O}$ has a remarkable negative correlation with precipitation amount, with a coefficient of $-0.56(n=62$, $p<0.0001)$ which is better than that of $\operatorname{Bomi}(R=-0.26$, $n=57, p<0.05$ ), while the slope of the $\delta^{18} \mathrm{O}$ precipitation is -0.51 at Lhasa, lower than that at Bomi $(-0.34)$. The annual mean d excess at Lhasa $(7.9 \%)$ is
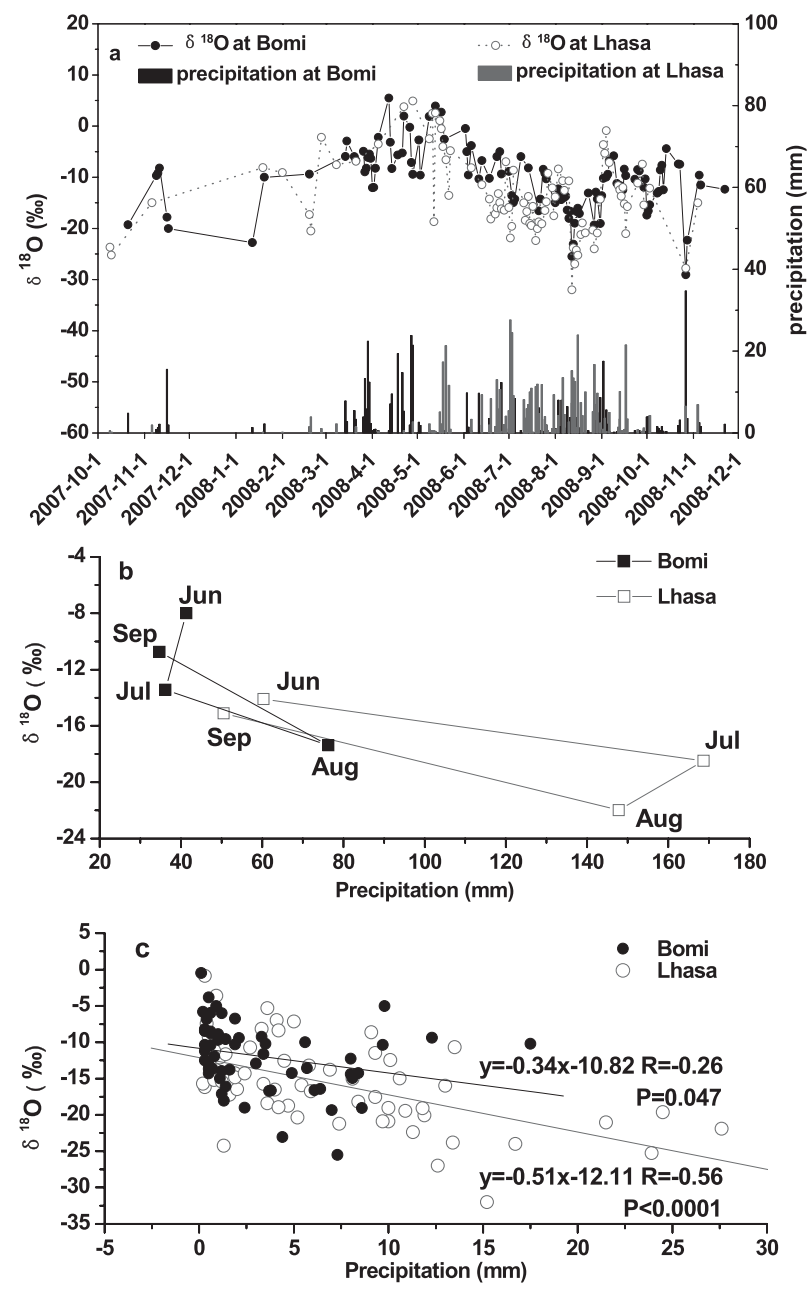

FIG. 5. (a) Comparison of daily $\delta^{18} \mathrm{O}$ in precipitation and precipitation amounts observed from October 2007 to November 2008 at Bomi (black) and Lhasa (gray). Relationships between summer precipitation $\delta^{18} \mathrm{O}$ and precipitation amounts (b) on a monthly scale and (c) on an event basis. 
about $2 \%$ lower than that at Bomi. These differences may be explained by different moisture sources. Lhasa's moisture is mostly provided by monsoon flow, while Bomi receives moisture provided by different moisture advection paths (the westerlies, local recycling, and monsoon flow) resulting in a subdued precipitation amount effect. Long-term monthly observations available for Lhasa reveal that interannual precipitation $\delta^{18} \mathrm{O}$ levels are also driven by the amount effect (Tian et al. 2003).

\section{Comparison of observations with simulations from LMDZiso and ECHAMiso models}

The GNIP network initiated in 1961 provides longterm monthly data for a number of sites in the world. Through monitoring stations initiated in the 1990s, a multiyear dataset is available for some sites on the Tibetan Plateau. Here, we use three of these Tibetan sites (Lhasa, Bomi, and Tuotuohe) and two GNIP sites located in India (Mumbai and Shilong) with multiyear records (Fig. 1), previously described in section 2, to compare the observed seasonal patterns with LMDZiso and ECHAM4iso model outputs. For each model, we also compare two types of simulations, the free versus nudged simulations. The averaged data over the closest grid box compared with the observed data from monitoring stations. Note that the scale mismatch may contribute to the difference between observations and simulations.

\section{a. Spatial distribution of annual mean isotopes in precipitation in India and on the Tibetan Plateau}

Risi et al. (2010) have documented the validity of global simulations from LMDZiso at different scales. Figure 6 shows maps of simulated annual mean $\delta^{18} \mathrm{O}$ and $\mathrm{d}$ excess in precipitation in India and along the Tibetan Plateau. The nudged ECHAM4iso and LMDZiso results do capture the spatial pattern of precipitation $\delta^{18} \mathrm{O}$ and the increasing northward isotopic depletion (Table 3 ), although there are mismatches in some regions. The standard LMDZiso (hereafter LMDZiso $_{\text {ctrl }}$ ) and ECHAM simulate annual mean $\delta^{18} \mathrm{O}$ values close to the observations below 2000 and above $4500 \mathrm{~m}$, but they fail to capture the strongly depleted $\delta^{18} \mathrm{O}$ values between 2000 and $4500 \mathrm{~m}$ (e.g., Bomi and Lhasa). This may be due to too a weak history of distillation upstream resulting from the underestimated precipitation on the foothills. Satisfactorily, the zoomed LMDZiso (hereafter LMDZiso ${ }_{h r}$ ) successfully simulated the lower $\delta^{18} \mathrm{O}$ along the Himalayas and the Tibetan Plateau as the most depleted $\delta^{18} \mathrm{O}$ region, matching better with the observations. This demonstrates that the improved spatial resolution is crucial for realistic simulations. Thanks to the high-resolution topography representation, the air masses undergo more distillation before arriving on the Tibetan Plateau (discussed in detail in section $4 \mathrm{~b}$ ). Thus, the zoomed annual mean $\delta^{18} \mathrm{O}$ values are lower than the standard simulations, with a depletion of $\sim 5 \%$, and match the observed $\delta^{18} \mathrm{O}$ in precipitation.

Simulations for both models show the "temperature effect," amount effect (Risi et al. 2010), and "altitude effect" used to reconstruct the history of the HimalayanTibetan Plateau uplift, which is critical to understand past Asian monsoon evolutionary patterns (Ramstein et al. 1997). Precipitation isotopic data collected at these five stations suggest a $\delta^{18} \mathrm{O}$ versus elevation gradient of $-0.3 \%$ o $(100 \mathrm{~m})^{-1}\left(R^{2}=0.48\right.$; see Fig. 7$)$, in agreement with previous Tibetan Plateau analyses (Hou et al. 2003; Tian et al. 2008). The overall simulated $\delta^{18} \mathrm{O}$-altitude relationships are rather consistent with the observations, with mean slopes of $-0.2 \%(100 \mathrm{~m})^{-1}$ for all simulations. In winter, the observed $\delta^{18} \mathrm{O}$-altitude relationship is significant in this region with a slope of $-0.6 \%(100 \mathrm{~m})^{-1}$, and all simulations underestimate this $\delta^{18} \mathrm{O}$-altitude relationships with slopes of $-0.3 \%$ o $(100 \mathrm{~m})^{-1}$ (even lower for $\mathrm{LMDZisO}_{\mathrm{hr}}$ simulation). In summer, all simulations again underestimate the $\delta^{18} \mathrm{O}$-altitude relationship with slopes of $-0.1 \%(100 \mathrm{~m})^{-1}$ from LMDZiso ctrl,$-0.15 \%$ o $(100 \mathrm{~m})^{-1}$ for LMDZiso $_{\mathrm{hr}}$, and $-0.2 \%(100 \mathrm{~m})^{-1}$ from ECHAM, all of which are less than the slope of $-0.3 \%$ $(100 \mathrm{~m})^{-1}$ obtained from observations. At the locations of the Tibetan Plateau monitoring stations, models have a higher elevation on average (because they cannot resolve the subgrid valley topography) and strongly overestimate the local precipitation amount (Table 3); it is therefore surprising that the models capture reasonably well the overall elevation gradient. Finally, the model results overestimate the elevation effect for the highaltitude sites (between 2000 and $5000 \mathrm{~m}$ ) with large simulated slopes $\left[-0.5 \%(100 \mathrm{~m})^{-1}\right]$. While clearly improving the seasonal cycle of precipitation isotopic composition in the Tibetan Plateau, the zoomed simulation does not capture the right amplitude of the altitude effects on d excess or $\delta^{18} \mathrm{O}$, especially in winter. The fact that observed slopes differ at low and high elevations, and that models underestimate elevation impacts at middle elevations but overestimate these elevation impacts for high-elevation locations, clearly brings into question the use of isotopic AGCMs to refine paleoelevation reconstructions.

The spatial distribution of the annual mean $d$ excess in precipitation is not as well simulated as $\delta^{18} \mathrm{O}$ in all of the models. Both $\mathrm{LMDZisO}_{\text {ctrl }}$ and ECHAM overestimate the $\mathrm{d}$ excess in precipitation around the Himalayas and show a stable d-excess spatial distribution, but $\mathrm{LMDZisO}_{\mathrm{hr}}$ underestimates the $\mathrm{d}$ excess in this region while also strongly overestimating the d excess at Mumbai (Fig. 6). ECHAM reproduces the d-excess altitude relationship 

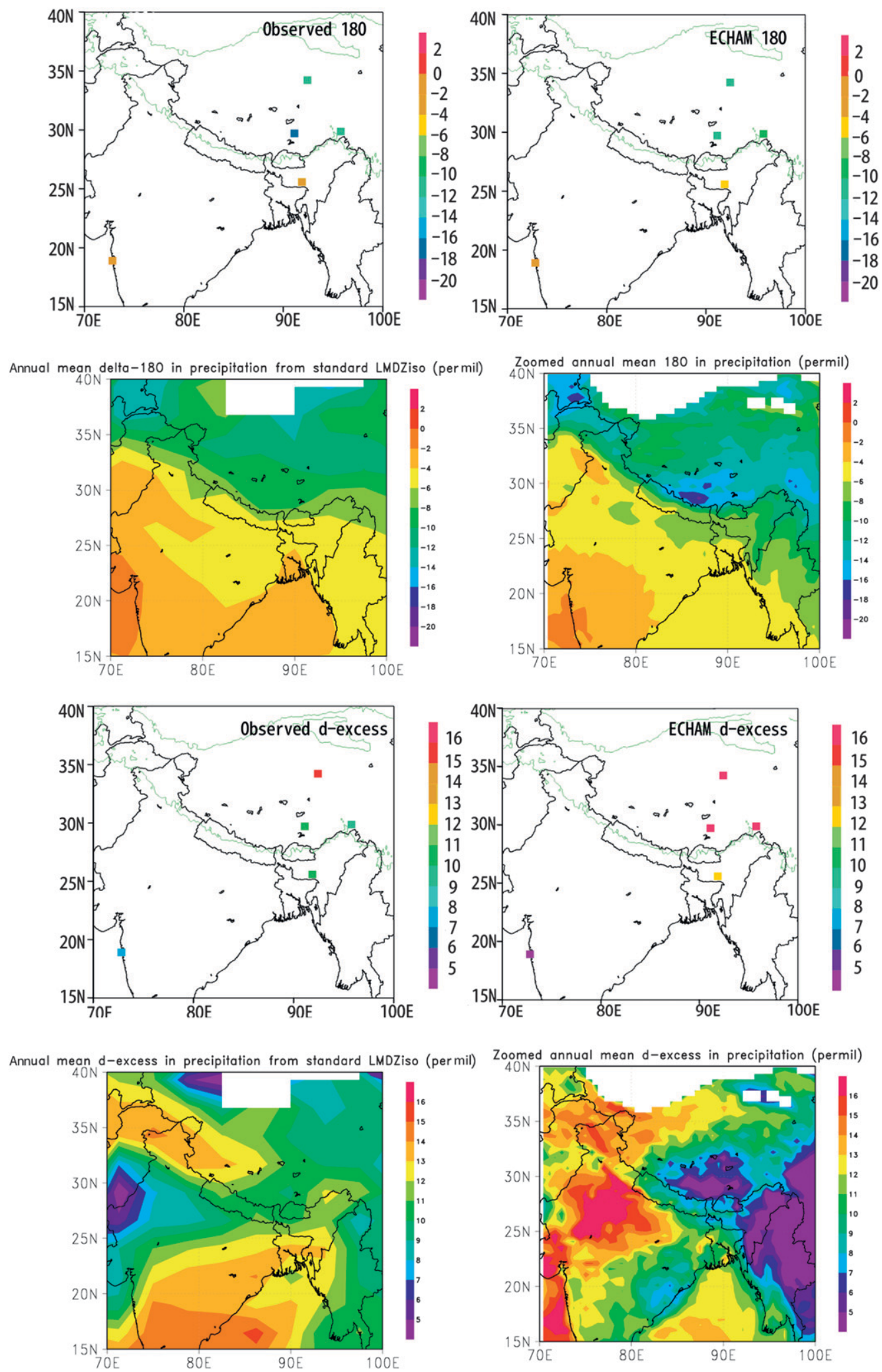

FIG. 6. Spatial variations of $\delta^{18} \mathrm{O}$ and d excess in precipitation from observations and three simulations (ECHAM4iso, standard LMDZiso, and zoomed LMDZiso) in study region. Annual mean data are displayed. 
TABLE 3. Summary of observed-modeled isotope and meteorological data from the standard LMDZ model for five stations.

\begin{tabular}{|c|c|c|c|c|c|}
\hline & Mumbai & Shilong & Bomi & Lhasa & Tuotuohe \\
\hline Lat & $18^{\circ} 54^{\prime} \mathrm{N}$ & $25^{\circ} 34^{\prime} \mathrm{N}$ & $29^{\circ} 51^{\prime} \mathrm{N}$ & $29^{\circ} 42^{\prime} \mathrm{N}$ & $34^{\circ} 13^{\prime} \mathrm{N}$ \\
\hline Lon & $72^{\circ} 49^{\prime} \mathrm{E}$ & $91^{\circ} 53^{\prime} \mathrm{E}$ & $95^{\circ} 47^{\prime} \mathrm{E}$ & $91^{\circ} 08^{\prime} \mathrm{E}$ & $92^{\circ} 26^{\prime} \mathrm{E}$ \\
\hline Alt (m) & 10 & 1598 & 2730 & 3658 & 4533 \\
\hline LMDZisoctrl alt (m) & 0 & 1746 & 3462 & 3854 & 4704 \\
\hline ECHAM alt (m) & 137 & 1365 & 3639 & 4240 & 4889 \\
\hline Obs period & 1960-78 & 1966-78 & 2008 & 1996-2004 & 1991-99 \\
\hline LMDZiso $_{\text {ctrl }}$ simulated period & 1979-2007 & 1979-2007 & 1979-2007 & 1979-2007 & 1979-2007 \\
\hline ECHAM simulated period & 1970-2001 & 1970-2001 & 1970-2001 & 1970-2001 & 1970-2001 \\
\hline Annual temperature $\left({ }^{\circ} \mathrm{C}\right)$, obs & 27.1 & 14.7 & 12.2 & 7.7 & -3.8 \\
\hline Simulated by LMDZiso $_{\text {ctrl }}$ & 26.3 & 19.9 & 0.1 & -4.5 & -8.6 \\
\hline Simulated by ECHAM & 29.4 & 15.8 & 2.1 & -1.7 & -9.4 \\
\hline Annual rainfall $(\mathrm{mm})$, obs & 1984.8 & 2156.4 & 826.4 & 627.3 & 262.3 \\
\hline Simulated by LMDZiso $_{\text {ctrl }}$ & 453.6 & 939.9 & 1288.4 & 2083.8 & 350.2 \\
\hline Simulated by ECHAM & 479.9035 & 1464.74 & 1202.467 & 1298.347 & 569.9004 \\
\hline Weighted $\delta^{18} \mathrm{O}(\%)$, obs & -1.51 & -3.67 & -11.81 & -16.21 & -11.95 \\
\hline Simulated by LMDZiso $\mathrm{ctrl}_{\text {le }}$ weighted $\delta^{18} \mathrm{O}(\%)$ & -1.12 & -5.50 & -6.55 & -9.65 & -10.89 \\
\hline Simulated by ECHAM weighted $\delta^{18} \mathrm{O}(\%)$ & -1.55842 & -5.39849 & -9.65947 & -10.6024 & -11.2651 \\
\hline
\end{tabular}

more reasonably with a slope of $0.24 \%(100 \mathrm{~m})^{-1}(R=$ 0.92 ) while the observed d-altitude slope is $0.12 \%$ $(100 \mathrm{~m})^{-1}(R=0.78)$. The standard and zoomed $\mathrm{d}$ excesses fail to reproduce this relationship.

\section{b. Seasonal cycles of stable isotopes in precipitation in India and on the Tibetan Plateau}

Figure 8 shows the simulated seasonal cycles of temperature, precipitation amount, $\delta^{18} \mathrm{O}$, and d excess in precipitation over five GNIP stations (including our new measurements for Bomi, Lhasa, and Tuotuohe). We can therefore compare the modeled results with the observations (Figs. 2 and 8 ). From south to north, both models reproduce the seasonal patterns of temperature to some extent, despite systematic biases. The nudged LMDZiso (hereafter LMDZiso $_{\text {ctrl }}$ ) simulation is $6^{\circ} \mathrm{C}$ too warm during the spring at Shilong, but underestimates Tibetan Plateau temperatures by up to $10^{\circ} \mathrm{C}$. The comparison between the free AMIP simulation and the nudged simulation reveals a slight improvement in the seasonal cycle of temperature with the nudging at Mumbai and Shilong, which is consistent with the results of Yoshimura et al. (2008). In contrast, the nudging deepens the model cold bias from LMDZiso for the Tibetan Plateau. This means that the LMDZiso model biases are not linked with the large-scale atmospheric dynamics and altitude difference (Table 3) but to model parameterizations, which can include, for instance, land surface properties (albedo and latent and sensible heat fluxes), boundary layer characteristics, and/or cloud properties (Kripalani et al. 2007a; Kripalani et al. 2007b). ECHAM performs relatively well for temperatures at Mumbai and Shilong, but also shows a $7^{\circ} \mathrm{C}$ systematic cold bias for the Tibetan Plateau. With ECHAM, the nudging slightly enhances the cold winter-spring bias at Lhasa, but induces much warmer temperatures in Tuotuohe, in better agreement with the observations. For this location, driving the model toward the observed large-scale wind fields clearly improves the realism of the simulated climate.

Regarding the precipitation seasonal cycle, nudged simulations of both models capture the pattern of the precipitation seasonal cycle, but strongly underestimate the precipitation amounts (by $60 \%-70 \%$ for LMDZiso

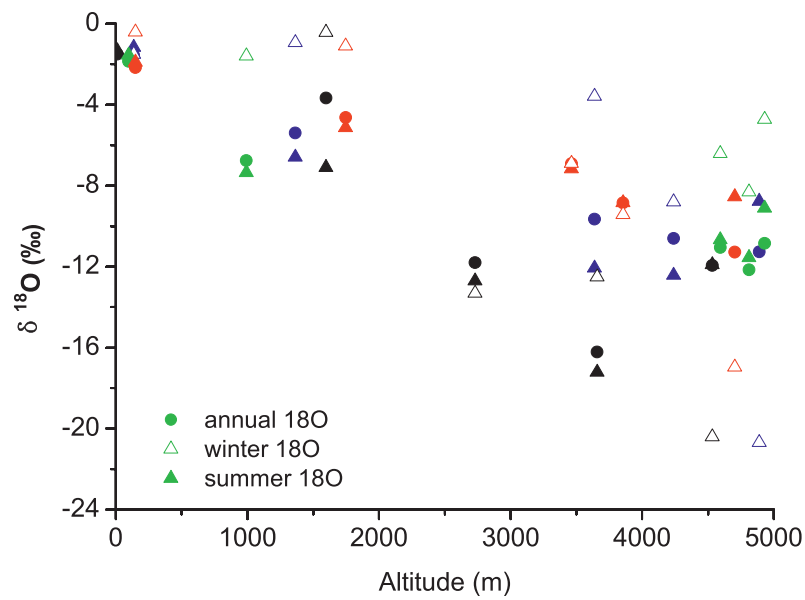

FIG. 7. Annual mean (filled circles), summer (black triangles), and winter (white triangles) variations of precipitation-weighted $\delta^{18} \mathrm{O}$ for observations (black), LMDZiso ctrl (red), $\mathrm{LMDZisO}_{\mathrm{hr}}$ (green), and ECHAM (blue) as a function of site elevation. Note that, due to the model grids, elevations for the geographical locations of Bomi, Lhasa, and Tuotuohe are systematically higher in the model "averaged topography" than the actual elevation of the valleys where the observations are conducted. The lower elevation for the coarser-resolution simulations (in apparent better agreement with the data) reflects the underestimated average elevation of the Tibetan plateau at coarse resolution. 

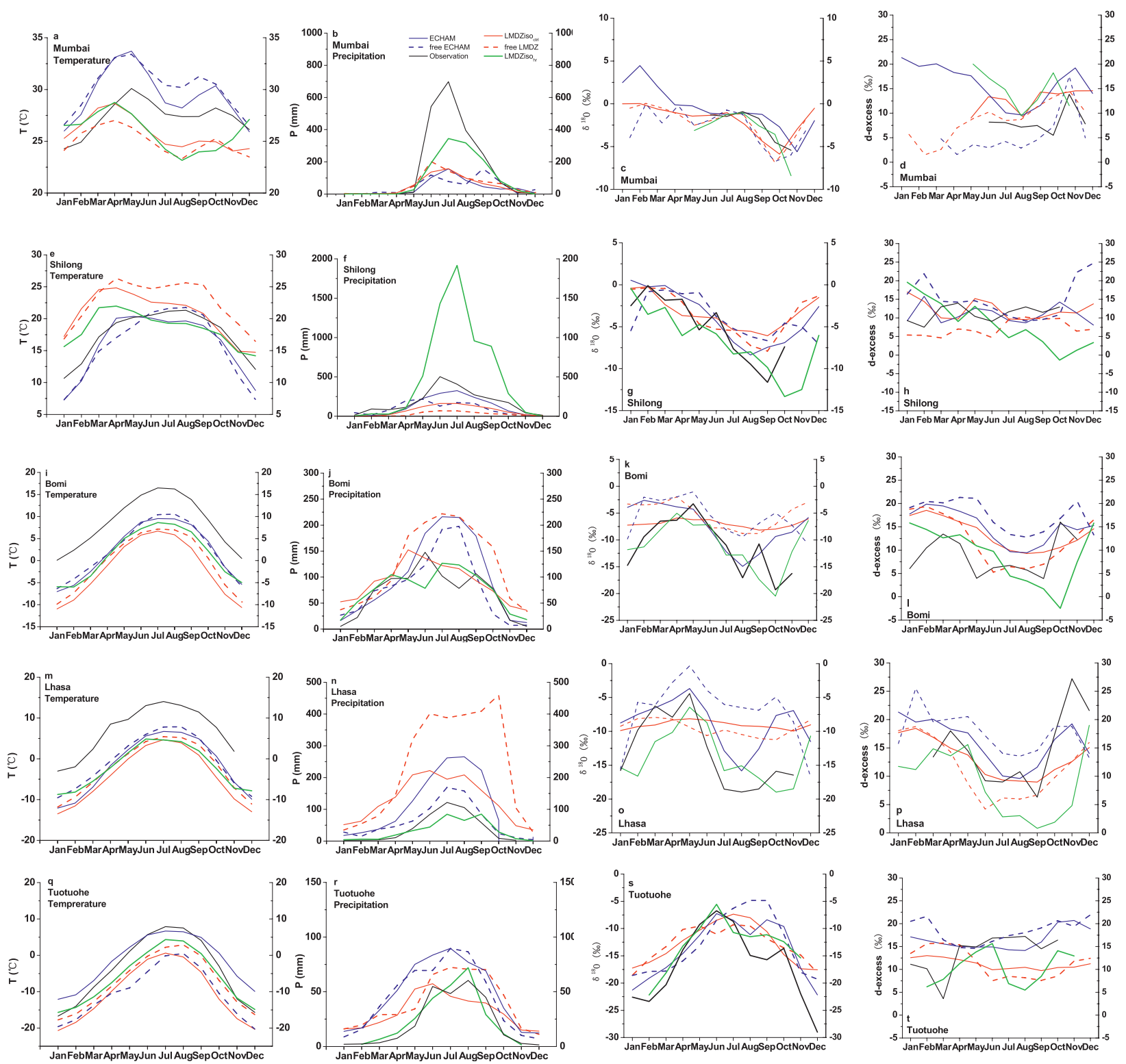

FIG. 8. Nudged multiyear monthly averages of climatology and stable isotopic compositions of precipitation (from left to right: air temperature, precipitation amount, $\delta^{18} \mathrm{O}$, and d excess in precipitation) observed (black) from south to north and compared with simulations from LMDZiso (red, standard simulation; green, zoomed simulation) and ECHAM (blue). Solid lines show the nudged simulations, while dashed lines show the free simulations. Note that, for readability, different vertical-axes scales have been used for $\delta^{18} \mathrm{O}$ and d excess. We used the standard simulations from LMDZiso for $29 \mathrm{yr}$ (1979-2007), zoomed simulations from LMDZiso for 3 yr (2005-07), and from ECHAM for $31 \mathrm{yr}$ (1970-2000). The lack of Mumbai data arises from a shortage of sampled precipitation and data in the IAEA database, as well as in model outputs.

and $0 \% \sim 75 \%$ for ECHAM, respectively) in India, while both models overestimate the precipitation amounts on the Tibetan Plateau. For LMDZ, the nudging clearly improves the hydrological cycle compared to the free simulation, which is even drier at Shilong and wetter in Tibet. For ECHAM, the nudging enhances the model wet bias in summer for Bomi and Lhasa. Overestimating the precipitation over high-elevation regions and underestimating it over nearby plains is a widespread bias in GCMs (Codron and Sadourny 2002).

The temperature in the zoomed simulation is not remarkably improved at Mumbai and Shilong, but it is slightly closer to the observations at the Tibetan stations, compared with simulations from $\mathrm{LMDZiso}_{\text {ctrl }}$. The correlation coefficient for the precipitation amount from $\mathrm{LMDZiso}_{\mathrm{hr}}$ is $0.72(p<0.0001)$, much higher than 
that from $\mathrm{LMDZiso}_{\text {ctrl }}(R=0.50, p<0.0001)$. The model performs better for precipitation on the Tibetan Plateau than for India. The zoomed model simulates more annual precipitation at Mumbai and Shilong. Although there are differences between the simulated and observed variations of precipitation during spring and summer, zoomed simulations can realistically reproduce the seasonal precipitation patterns at Bomi and Lhasa. At Tuotuohe, the precipitation simulated by LMDZ is almost coincident with the observations.

To summarize, both models exhibit a summer dry bias for India together with a year-round cold and wet bias for the Tibetan Plateau. Part of the model-data mismatches may arise from the model resolutions and the difficulties involved with capturing the complex influences of the south Tibetan topography, but the comparison between the nudged and free simulations reveals that they cannot be explained by large-scale dynamics and, therefore, point to the model physical parameterizations. Consistent with earlier model intercomparisons, ECHAM seems to perform better than LMDZ regarding monsoon precipitation (Kripalani et al. 2007a,b).

The performances of LMDZ and ECHAM in simulating stable isotopes in precipitation are also scrutinized (Fig. 8). Despite temperature and precipitation biases, LMDZ and ECHAM do capture the seasonal pattern of precipitation $\delta^{18} \mathrm{O}$ to some extent. At Mumbai, both models show $\delta^{18} \mathrm{O}$ seasonal cycles consistent with the observations, with minimum values in late summerearly autumn. At Shilong, the ECHAM model captures correctly the seasonal variations of $\delta^{18} \mathrm{O}$ in precipitation, but slightly underestimates the isotopic depletion observed in September. For this location, LMDZiso ctrl $_{\text {- }}$ shows too flat a seasonal cycle and underestimates the summer depletion by about $5 \%$; this was expected from the model dry bias for this area. On the Tibetan Plateau (Bomi and Lhasa), LMDZiso ${ }_{\text {ctrl }}$ shows rather stable isotopic values all year round and fails to capture the observed seasonality. Thanks to a better simulation of the monsoon precipitation on the Tibetan Plateau, ECHAM does reasonably capture the summer's depleted $\delta^{18} \mathrm{O}$ values, which are affected by the amount effect, but, similarly to $\mathrm{LMDZ}_{\mathrm{ctrl}}$ it overestimates the winter $\delta^{18} \mathrm{O}$. Finally, both models capture correctly the pattern of $\delta^{18} \mathrm{O}$ at Tuotuohe, but again exhibit too high isotopic values in winter and not enough depletion in late summer (August-September). The nudged seasonal cycles of d excess are similar for both models at Shilong, Bomi, and Lhasa, albeit with different simulated dexcess levels in October and in November. Compared with the observations, both models capture the seasonal pattern and amplitude of $d$ excess at Mumbai and Lhasa, but again fail to reproduce the seasonal d-excess cycle at other stations. At Tuotuohe, the ECHAM simulates significantly higher d excess $(3 \% \sim 10 \%$ ) than that of LMDZiso $_{\text {ctrl }}$ all year round, while the simulated $\delta^{18} \mathrm{O}$ values are similar.

For ECHAM, the nudged simulation clearly improves the realism of the simulated precipitation $\delta^{18} \mathrm{O}$, especially on the Tibetan Plateau (Figs. 8k to 80). Both the free and standard LMDZ simulations produce too flat precipitation $\delta^{18} \mathrm{O}$ seasonal cycles, and the nudging even reduces the magnitude of the simulated seasonal cycle. The nudging however improves the simulation of $\mathrm{d}$ excess for both models, especially at Mumbai and Shilong.

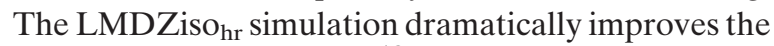
forecasts of precipitation $\delta^{18} \mathrm{O}$ and d-excess patterns, especially on the Tibetan Plateau. On the Tibetan Plateau, the zoomed simulations of precipitation $\delta^{18} \mathrm{O}$ are very close to the observations, with a correlation coefficient of $0.86(p<0.0001)$. In fact, the zoomed simulation induces a very large precipitation amount at Shilong, which enhances depletion, leading to low precipitation $\delta^{18} \mathrm{O}$ on the Tibetan Plateau in agreement with the observations. The fact that $\delta^{18} \mathrm{O}$ is significantly improved in $\mathrm{LMDZiso}_{\mathrm{hr}}$ compared to LMDZiso $_{\text {ctrl }}$, while temperature and precipitation are not, confirms that the isotopic composition of water constitutes an added value to investigate the water cycle compared to meteorological measurements only, since it reflects the dehydration history and processes along trajectories that are not readily identifiable in meteorological data (Worden et al. 2007; Galewsky and Hurley 2010). However, the zoomed simulation does not improve the seasonal cycle of $\mathrm{d}$ excess, which is controlled by factors other than $\delta^{18} \mathrm{O}$.

The performance of the models in capturing the seasonality of precipitation $\delta^{18} \mathrm{O}$ and d excess is obviously affected by model biases for temperature and precipitation, albeit in a complex manner. Given their coarse spatial resolutions, models do not capture intense storms associated with strong isotopic depletion, and despite the nudging with large-scale observed wind fields, may not represent correctly the seasonal shifts in airmass trajectories. Compared with other Tibetan stations, the models perform better for precipitation isotopic composition where the monsoon influence is weakest. This indicates that the simulation of the monsoon is pivotal to the accurate simulation of the seasonal variations for both models.

\section{c. Comparison with daily observations at Bomi and Lhasa}

Because the nudged ECHAM simulation does not cover 2008, we have to restrict this model-data comparison 

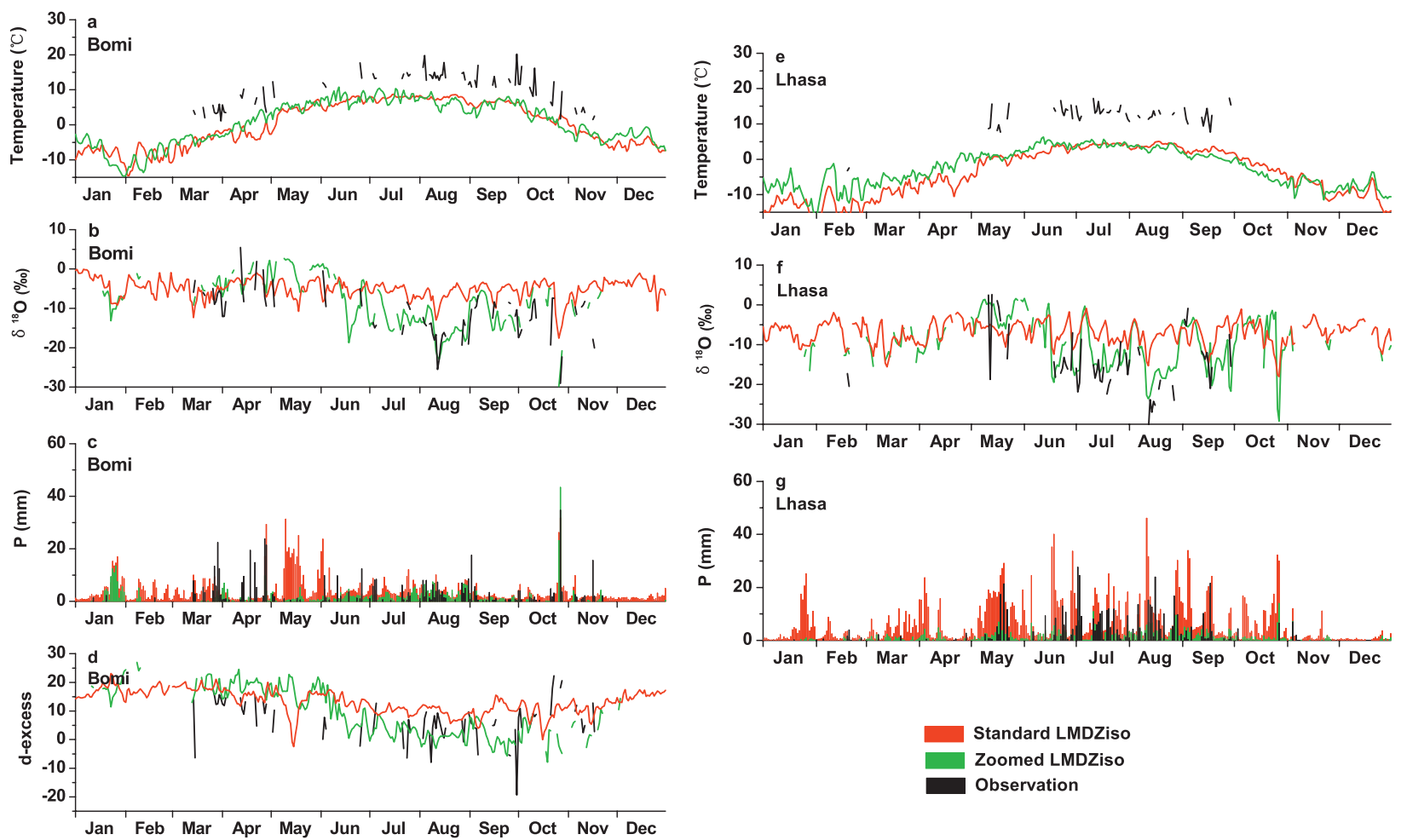

FIG. 9. Daily variabilities of (a),(e) temperature, (b),(f) $\delta^{18} \mathrm{O}$ in precipitation, (c),(g) precipitation amount, and (d) d excess for the

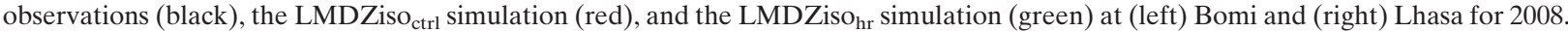

to LMDZiso. The LMDZiso nudged simulation offers the possibility of comparing the modeled day-to-day variability with the Bomi and Lhasa data between January and December 2008 (Fig. 9). At the event scale, LMDZiso ${ }_{\text {ctrl }}$ strongly overestimates the magnitude of the Bomi and Lhasa precipitation amounts and simulates systematically too high $\delta^{18} \mathrm{O}$ values, with very weak seasonal amplitude. The model does not capture the high spring $\delta^{18} \mathrm{O}$ values and the magnitude of summer depletion. LMDZiso $_{\mathrm{hr}}$ dramatically improves the event simulation of precipitation and precipitation $\delta^{18} \mathrm{O}$ with correlation coefficients of 0.3 and $0.71(p<0.0001)$, respectively, which are much higher than those from LMDZiso $_{\text {ctrl }}(0.09$ for precipitation amount and 0.34 for precipitation $\delta^{18} \mathrm{O}, p<$ 0.0001 ). The zoomed simulation reproduces the observed seasonal magnitudes with spring high $\delta^{18} \mathrm{O}$ and summer low $\delta^{18} \mathrm{O}$ values (Figs. 9b and 9f). Although the zoomed model overestimates the precipitation amount in spring and autumn, the simulation reproduced heavy precipitation events at Bomi; while the magnitude of the heavy precipitation is not reproduced and $\mathrm{LMDZisO}_{\mathrm{hr}}$ simulates too much precipitation during the spring and autumn. The zoomed model still cannot capture the exact seasonal amplitude of temperature, underestimating its range by more than $1^{\circ} \mathrm{C}$ (Figs. 9a and 9e). The zoomed $\mathrm{d}$ excess does not capture the pattern of observed d-excess variation, especially in spring, and underestimates the magnitude of the d-excess fluctuations.

The lack of model $\delta^{18} \mathrm{O}$ depletion in LMDZiso $_{\text {ctrl }}$ during summer is unlikely to be linked with interannual variability, which is very small in LMDZ outputs, and is further supported by the comparison of LMDZ with the longer Lhasa records. The lack of summer-autumn depletion and d-excess seasonality can be linked to different processes, such as the model condensation processes, or the model moisture source and transport.

\section{Conclusions}

The local climate, together with the origin and transport of moisture and precipitation processes, are crucial factors that affect the spatial and temporal variabilities of stable isotopes in precipitation. In this paper, we have shown new results from two stations along the southeastern Tibetan Plateau, at Bomi and Lhasa, where precipitation sampling was achieved on an event basis. The links with local precipitation and temperature have been analyzed at the event and on a monthly basis and these show rather consistent results. The complex seasonal cycle of precipitation $\delta^{18} \mathrm{O}$ in this area cannot be understood without taking into account airmass trajectories, which we did using backward trajectories calculated 
from the LMDZ model. Episodic winter precipitation events mostly arise from the westerlies. During the summer, the monsoon produces the lowest $\delta^{18} \mathrm{O}$ values both at Bomi and Lhasa. In spring, different moisture transports result in differences in precipitation $\delta^{18} \mathrm{O}$ at Bomi and Lhasa. Similarities between Bomi and Lhasa are observed in summer and point to the advection of monsoon flow from Bomi to Lhasa along the Brahmaputra River valley, a regional flow pattern that cannot be resolved by lowresolution AGCMs.

Our study has shown that the amount effect is observed with the monsoon's onset, which relates high precipitation amounts with strongly depleted $\delta^{18} \mathrm{O}$, and explained the links between shifts in moisture origin and southern Tibetan $\delta^{18} \mathrm{O}$ values, in particular the highest $\delta^{18} \mathrm{O}$ levels in spring and the most depleted levels in summer. Further quantitative understand could be investigated in simulations including the tagging of moisture sources (Delaygue et al. 2000; Masson-Delmotte et al. 2008).

The available observations now enable systematic comparisons with isotopic AGCMs regarding the isotopic variability along precipitation events, spatial patterns, and seasonal cycles. Both LMDZiso $_{\text {ctrl }}$ and ECHAMiso share common biases in this complex Tibetan Plateau region, notably deficient precipitation at low latitudes and too-wet and too-cold conditions on the Tibetan Plateau. They generally simulate stronger correlations of $\delta^{18} \mathrm{O}$ with precipitation and temperature than are observed [something that has been observed before; Hoffmann et al. (2005)], and underestimate the variability of $\delta^{18} \mathrm{O}$ at seasonal and event scales. In particular, LMDZiso $_{\text {ctrl }}$ underestimates the seasonal amplitude of $\delta^{18} \mathrm{O}$ in the southern Tibetan Plateau, probably in relationship to the upstream processes and a dominant westerly flow; while generally improving the simulated precipitation amount, the nudging enhances the model cold bias. Nudging ECHAM amplifies the difference in the precipitation amounts at Bomi and Lhasa, but it is effective at producing realistic simulated $\delta^{18} \mathrm{O}$ results in precipitation in our study region. In winter, both models overestimate the effects of temperature and precipitation on $\delta^{18} \mathrm{O}$. In summer, both models underestimated the amount effects, especially at Mumbai and Shilong, where they are too dry. In general, ECHAM performs better than LMDZiso on the regional climate and precipitation isotopic composition. The model bias however remains significant, typically less than $4 \%$ for ECHAM but reaching $10 \%$ for LMDZiso. Although ECHAM is able to simulate reasonably well the amount effect and the spatial distribution of the precipitation $\delta^{18} \mathrm{O}$, it still fails to capture the southern Tibetan plateau $\delta^{18} \mathrm{O}$ seasonal cycle and winter values.
The LMDZiso $_{\text {hr }}$ version makes simulations more realistic thanks to an improved representation of regional topography. Although it is too wet at Shilong, the Tibetan precipitation is much closer to the observations. The simulation of daily and monthly precipitation $\delta^{18} \mathrm{O}$ is more reasonable and shows realistic seasonal variations. The improved spatial resolution is therefore crucial for correct simulations of Tibetan Plateau precipitation and $\delta^{18} \mathrm{O}$.

The overall simulated $\delta^{18} \mathrm{O}$ versus elevation gradient is within the range of observations, although it is underestimated in winter and at low elevations. Both $\mathrm{LMDZ}_{\mathrm{ctrl}}$ and ECHAM show wet and cold biases between 2000 and $4500 \mathrm{~m}$. At high altitudes, models simulate steeperelevation $\delta^{18} \mathrm{O}$ than is observed. Because of changing $\delta^{18} \mathrm{O}$-elevation slopes with altitude, we are suspicious of the reliability of estimating the paleo-elevation based on the oxygen isotopic composition of precipitation.

This study shows the potential of Tibetan Plateau precipitation isotopic composition databases for testing the realism of the water cycle simulated by isotopic AGCMs and the importance of spatial resolution for realistic simulations. There is a strong need to maintain long-term observations at the monthly time frame, to improve the spatial coverage of the datasets, and to develop event-based studies that are necessary to better understand the exact processes at play, including, in the future, the parallel monitoring of water vapor isotopic composition. Our comparison with two AGCMs shows very large systematic biases in the AGCMs regarding both the regional climate and the properties of water stable isotopes in precipitation. The complex topographic features add to the difficulties in correctly simulating moisture advection from the lowlands to the Tibetan Plateau. Second-order isotopic data such as deuterium excess and oxygen 17 are expected to bring further constraints on the water cycle, moisture origin, local recycling, and convective processes. However, models that can correctly capture these second-order tracers remain a future research effort due to the large biases in secondorder isotopic data, which are probably linked to land surface, convection, and cloud representations. Nudging does not resolve these parameterization problems but helps to build a framework within which the synopticscale atmospheric dynamics is realistic.

While isotopic AGCMs have previously been used to assess the stability of the isotope-climate relationships at polar locations, there is still much to be done before they can be used with confidence for improving paleoclimate reconstructions conducted with water stable isotopes in the Tibetan Plateau area or for providing constraints on paleo-elevation. Systematic comparisons between isotopic AGCMs should be expanded to other 
models than the two AGCMs explored here. The major model-data mismatches shown here are also strong limitations for confidently forecasting the regional impacts of increasing greenhouse gas concentrations. This is particularly frustrating when considering the societal importance of the southern Tibetan Plateau and its glaciers, which serve as a "water tower" for some of the world's largest rivers and provide water to many surrounding countries.

Acknowledgments. We thank Sandrine Bony for her contribution in the development of the LMDZiso model and fruitful discussions, Yang Wei for the initial field work, and Francoise Vimeux for her constructive comments. We also thank Sonia Falourd and Bénédicte Minster for their help with isotopic measurements. This work is supported by the GIS Pluies-Tibet, the French Embassy in China, the National Natural Science Foundation of China (Grants 40830638 and 40810019001), the External Cooperation Program of the Chinese Academy of Sciences (Grant GJHZ0960) and the CAS/SAFEA International Partnership Program for Creative Research Teams. Special thanks are given to anonymous reviewers for very helpful suggestions. Our thanks are also given to all those involved with precipitation sample collection.

\section{REFERENCES}

Aizen, V. B., E. M. Aizen, D. R. Joswiak, K. Fujita, N. Takeuchi, and S. A. Nikitin, 2006: Climatic and atmospheric circulation pattern variability from ice-core isotope/geochemistry records (Altai, Tien Shan and Tibet). Ann. Glaciol., 43, 49-60.

Araguas-Araguas, L., K. Froehlich, and K. Rozanski, 1998: Stable isotope composition of precipitation over Southeast Asia. J. Geophys. Res., 103 (D22), 28 721-28 742.

Bony, S., and K. A. Emanuel, 2001: A parameterization of the cloudiness associated with cumulus convection: Evaluation using TOGA COARE data. J. Atmos. Sci., 58, 3158-3183.

- C. Risi, and F. Vimeux, 2008: Influence of convective processes on the isotopic composition (delta O-18 and delta D) of precipitation and water vapor in the tropics: 1 . Radiativeconvective equilibrium and Tropical Ocean-Global Atmosphere-Coupled Ocean-Atmosphere Response Experiment (TOGA-COARE) simulations. J. Geophys. Res., 113, D19305, doi:10.1029/2008JD009942.

Chow, K. C., and J. C. L. Chan, 2009: Diurnal variations of circulation and precipitation in the vicinity of the Tibetan Plateau in early summer. Climate Dyn., 32, 55-73.

Ciais, P., and J. Jouzel, 1994: Deuterium and oxygen 18 in precipitation: A new isotopic model including mixed cloud processes. J. Geophys. Res., 99, 16 793-16 803.

Clark, I., and P. Fritz, 1997: Environmental Isotopes in Hydrogeology. CRC, 328 pp.

Codron, F., and R. Sadourny, 2002: Saturation limiters for water vapour advection schemes: Impact on orographic precipitation. Tellus, 54A, 338-349, doi:10.1034/j.1600-0870.2002.01265.x.

Coindreau, O., F. Hourdin, M. Haeffelin, A. Mathieu, and C. Rio, 2007: Assessment of physical parameterizations using a global climate model with stretchable grid and nudging. Mon. Wea. Rev., 135, 1474-1489.

Dansgaard, W., 1964: Stable isotopes in precipitation. Tellus, 16, 436-468.

Delaygue, G., V. Masson, J. Jouzel, and R. D. Koster, 2000: The origin of Antarctic precipitation: A modelling approach. Tellus, 52B, 19-36.

Emanuel, K. A., 1991: A scheme for representing cumulus convection in large-scale models. J. Atmos. Sci., 48, 2313-2329.

_ , and M. Zivkovic-Rothman, 1999: Development and evaluation of a convection scheme for use in climate models. J. Atmos. Sci., 56, 1766-1782.

Galewsky, J., and J. V. Hurley, 2010: An advection-condensation model for subtropical water vapor isotopic ratios. J. Geophys. Res., 115, D16116, doi:10.1029/2009JD013651.

Gao, D., H. Zou, and W. Wei, 1985: Influence of water vapor pass along the Yalungzangbo River on precipitation (in Chinese with English abstract). Meteor. Res., 3, 239-249.

Gates, W. L., 1992: AMIP: The Atmospheric Model Intercomparison Project. Bull. Amer. Meteor. Soc., 73, 1962-1970.

Gupta, S. K., R. D. Deshpande, S. K. Bhattacharya, and R. A. Jani, 2005: Groundwater delta O-18 and D-delta from central Indian Peninsula: Influence of the Arabian Sea and the Bay of Bengal branches of the summer monsoon. J. Hydrol., 303, 38-55.

Hoffmann, G., and M. Heimann, 1997: Water isotope modeling in the Asian monsoon region. Quat. Int., 37, 115-128, doi:10.1016/ 1040-6182(96)00004-3.

_ the ECHAM atmospheric general circulation model: A study on timescales from days to several years. J. Geophys. Res., 103 (D18), 16 871-16 896.

- J. Jouzel, and V. Masson, 2000: Stable water isotopes in atmospheric general circulation models. Hydrol. Processes, 14, 1385-1406.

_ M. Cuntz, M. Werner, and J. Jouzel, 2005: How much climate information is in the water isotopes?: A systematic comparison between the IAEA/GNIP isotope network and atmospheric general circulation models. Isotopes in the Water Cycle: Past, Present and Future of a Developing Science, P. K. Aggrawal, J. R. Gat, and K. F. O. Froehlich, Eds., Int. Atomic Energy Agency, 303-320.

Hou, S. G., V. Masson-Delmotte, D. Qin, and J. Jouzel, 2003: Modern precipitation stable isotope vs. elevation gradients in the High Himalaya. Comment on "A new approach to stable isotope-based paleoaltimetry: Implications for paleoaltimetry and paleohypsometry of the High Himalaya since the Late Miocene" by David B. Rowley et al. [Earth Planet. Sci. Lett., 188(2001) 253-268]. Earth Planet. Sci. Lett., 209, 395-399.

Hourdin, F., and Coauthors, 2006: The LMDZ4 general circulation model: Climate performance and sensitivity to parameterized physics with emphasis on tropical convection. Climate Dyn., 27, 787-813.

Hurrell, J. W., and K. E. Trenberth, 1999: Global sea surface temperature and analyses: Multiple problems and their implications for climate analysis, modeling, and reanalysis. Bull. Amer. Meteor. Soc., 80, 2661-2678.

Joussaume, S., R. Sadourny, and J. Jouzel, 1984: A general-circulation model of water isotope cycles in the atmosphere. Nature, $\mathbf{3 1 1}$, 24-29.

Jouzel, J., and L. Merlivat, 1984: Deuterium and O-18 in precipitationModeling of the isotopic effects during snow formation. J. Geophys. Res., 89 (D7), 1749-1757.

_ G. L. Russell, R. J. Suozzo, R. D. Koster, J. W. C. White, and W. S. Broecker, 1987: Simulations of the HDO and $\mathrm{H}_{2} \mathrm{O}-18$ atmospheric 
cycles using the NASA GISS general-circulation model-The seasonal cycle for present-day conditions. J. Geophys. Res., 92 (D12), 14 739-14 760.

— , and Coauthors, 1994: Stable water isotope behavior during the Last Glacial Maximum: A general circulation model analysis. J. Geophys. Res., 99, 25 791-25 801.

— construction from water isotopes in ice cores. J. Geophys. Res., 102 (C12), 26 471-26 487.

—, G. Hoffmann, R. D. Koster, and V. Masson, 2000: Water isotopes in precipitation: Data/model comparison for presentday and past climates. Quat. Sci. Rev., 19, 363-379.

Kripalani, R. H., J. H. Oh, and H. S. Chaudhari, 2007a: Response of the East Asian summer monsoon to doubled atmospheric $\mathrm{CO}_{2}$ : Coupled climate model simulations and projections under IPCC AR4. Theor. Appl. Climatol., 87, 1-28.

$\longrightarrow,-$, A. Kulkarni, S. S. Sabade, and H. S. Chaudhari, 2007b: South Asian summer monsoon precipitation variability: Coupled climate model simulations and projections under IPCC AR4. Theor. Appl. Climatol., 90, 133-159.

Kurita, N., and H. Yamada, 2008: The role of local moisture recycling evaluated using stable isotope data from over the middle of the Tibetan Plateau during the monsoon season. J. Hydrometeor., 9, 760-775.

Lee, J., I. Fung, D. J. DePaolo, and C. C. Henning, 2007: Analysis of the global distribution of water isotopes using the NCAR atmospheric general circulation model. J. Geophys. Res., 112, D16306, doi:10.1029/2006JD007657.

LeGrande, A. N., and G. A. Schmidt, 2009: Sources of Holocene variability of oxygen isotopes in paleoclimate archives. Climate Past, 5, 441-455.

Lin, Z., and X. Wu, 1990: A preliminary analysis about the tracks of moisture transportation on the Qinghai-Xizang Plateau (in Chinese with English abstract). Geogr. Res., 9, 30-49.

Liu, Z. F., L. Tian, T. D. Yao, and W. S. Yu, 2008: Seasonal deuterium excess in Nagqu precipitation: Influence of moisture transport and recycling in the middle of Tibetan Plateau. Environ. Geol., 55, 1501-1506.

Masson-Delmotte, V., and Coauthors, 2008: A review of Antarctic surface snow isotopic composition: Observations, atmospheric circulation, and isotopic modeling. J. Climate, 21, 3359-3387.

Mathieu, R., D. Pollard, J. E. Cole, J. W. C. White, R. S. Webb, and S. L. Thompson, 2002: Simulation of stable water isotope variations by the GENESIS GCM for modern conditions. J. Geophys. Res., 107, D4, doi:10.1029/2001JD900255.

Merlivat, L., and J. Jouzel, 1979: Global climate interpretation of the deuterium-oxygen 18 relationship for precipitation. J. Geophys. Res., 84, 5029-5033.

Nguyen, K. C., and J. L. McGregor, 2009: Modelling the Asian summer monsoon using CCAM. Climate Dyn., 32, 219-236.

Noone, D., and I. Simmonds, 2002: Associations between $\delta^{18} \mathrm{O}$ of water and climate parameters in a simulation of atmospheric circulation for 1979-95. J. Climate, 15, 3150-3169.

Ramstein, G., F. Fluteau, J. Besse, and S. Joussaume, 1997: Effect of orogeny, plate motion and land sea distribution on Eurasian climate change over the past 30 million years. Nature, 386, 788-795.

Rasch, P. J., and D. L. Williamson, 1990: Computational aspects of moisture transport in global-models of the atmosphere. Quart. J. Roy. Meteor. Soc., 116, 1071-1090.

Risi, C., S. Bony, F. Vimeux, and J. Jouzel, 2010: Water stable isotopes in the LMDZ4 general circulation model: Model evaluation for present day and past climates and applications to climatic interpretation of tropical isotopic records. J. Geophys. Res., 115, D12118, doi:10.1029/2009JD013255.

Roeckner, E., and Coauthors, 1996: The atmospheric general circulation model ECHAM-4: Model description and simulation of present-day climate. Max Planck Institute for Meteorology Tech. Rep. 218, 90 pp.

Rozanski, K., L. Araguas-Araguas, and R. Gonfiantini, 1992: Relation between long-term trends of oxygen-18 isotope composition of precipitation and climate. Science, 258, 981-985.

Schmidt, G. A., A. N. LeGrande, and G. Hoffmann, 2007: Water isotope expressions of intrinsic and forced variability in a coupled ocean-atmosphere model. J. Geophys. Res., 112, D10103, doi:10.1029/2006JD007781.

Sengupta, S., and A. Sarkar, 2006: Stable isotope evidence of dual (Arabian Sea and Bay of Bengal) vapour sources in monsoonal precipitation over north India. Earth Planet. Sci. Lett., 250, 511-521.

Shi, X. Y., Y. Q. Wang, and X. D. Xu, 2008: Effect of mesoscale topography over the Tibetan Plateau on summer precipitation in China: A regional model study. Geophys. Res. Lett., 35, L19707, doi:10.1029/2008GL034740.

Stewart, M. K., 1975: Stable isotope fractionation due to evaporation and isotopic exchange of falling waterdrops: Applications to atmospheric processes and evaporation of lakes. J. Geophys. Res., 80, 1133-1146.

Thompson, L. G., T. Yao, E. Mosley-Thompson, M. E. Davis, K. A. Henderson, and P. N. Lin, 2000: A high-resolution millennial record of the South Asian monsoon from Himalayan ice cores. Science, 289, 1916-1919.

Tian, L., V. Masson-Delmotte, M. Stievenard, T. Yao, and J. Jouzel, 2001: Tibetan Plateau summer monsoon northward extent revealed by measurements of water stable isotopes. J. Geophys. Res., 106 (D22), 28 081-28 088.

—, T. Yao, P. F. Schuster, J. W. C. White, K. Ichiyanagi, E. Pendall, J. Pu, and Y. Wu, 2003: Oxygen-18 concentrations in recent precipitation and ice cores on the Tibetan Plateau. J. Geophys. Res., 108, 4293, doi:10.1029/2002JD002173.

- - , K. MacClune, J. W. C. White, A. Schilla, B. Vaughn, R. Vachon, and K. Ichiyanagi, 2007: Stable isotopic variations in west China: A consideration of moisture sources. J. Geophys. Res., 112, D10112, doi:10.1029/2006JD007718.

, L. L. Ma, W. S. Yu, Z. F. Liu, C. L. Yin, Z. P. Zhao, W. Tang, and Y. Wang, 2008: Seasonal variations of stable isotope in precipitation and moisture transport at Yushu, eastern Tibetan Plateau. Earth Sci., 51, 1121-1128.

Tindall, J. C., P. J. Valdes, and L. C. Sime, 2009: Stable water isotopes in HadCM3: Isotopic signature of El Niño-Southern Oscillation and the tropical amount effect. J. Geophys. Res., 114, D04111, doi:10.1029/2008JD010825.

Uppala, S. M., and Coauthors, 2005: The ERA-40 Re-Analysis. Quart. J. Roy. Meteor. Soc., 131, 2961-3012.

Van Leer, B., 1977: Towards ultimate conservative difference scheme: IV. A new approach to numerical convection. J. Comput. Phys., 23, 276-299.

Vuille, M., M. Werner, R. S. Bradley, and F. Keimig, 2005: Stable isotopes in precipitation in the Asian monsoon region. J. Geophys. Res., 110, D23108, doi:10.1029/2005JD006022.

Worden, J., D. Noone, and K. Bowman, 2007: Importance of rain evaporation and continental convection in the tropical water cycle. Nature, 445, 528-532.

Xin, X., Z. Li, R. Yu, and T. Zhou, 2008: Impacts of upper tropospheric cooling upon the late spring drought in East Asia simulated by a regional climate model. Adv. Atmos. Sci., 25, 555-562. 
Xu, B. Q., and Coauthors, 2009: Black soot and the survival of Tibetan glaciers. Proc. Natl. Acad. Sci. USA, 106, 22 114-22 118.

Yao, T. D., Y. Q. Liu, S. C. Kang, N. Z. Jiao, Y. H. Zeng, X. B. Liu, and Y. J. Zhang, 2008: Bacteria variabilities in a Tibetan ice core and their relations with climate change. Global Biogeochem. Cycles, 22, GB4017, doi:10.1029/2007GB003140.

Yoshimura, K., T. Oki, N. Ohte, and S. Kanae, 2003: A quantitative analysis of short-term O-18 variability with a Rayleigh-type isotope circulation model. J. Geophys. Res., 108, 4647, doi:10. 1029/2003JD003477.

, M. Kanamitsu, D. Noone, and T. Oki, 2008: Historical isotope simulation using reanalysis atmospheric data. J. Geophys. Res., 113, D19108, doi:10.1029/2008JD010074.
Yu, W. S., T. D. Yao, L. Tian, Y. M. Ma, K. P. Ichlyanagi, Y. Wang, and W. Z. Sun, 2008: Relationships between delta O-18 in precipitation and air temperature and moisture origin on a south-north transect of the Tibetan Plateau. Atmos. Res., 87, 158-169.

Yurtsever, Y., and J. Gat, 1981: Atmospheric waters. Stable Isotope Hydrology: Deuterium and Oxygen-18 in the Water Cycle, J. R. Gat and R. Gonfiantini, Eds., International Atomic Energy Agency Tech. Rep. Series, Vol. 210, 103-142.

Zhang, X. P., J. M. Liu, Y. Q. He, L. D. Tian, and T. D. Yao, 2005: Humidity effect and its influence on the seasonal distribution of precipitation delta O-18 in monsoon regions. Adv. Atmos. Sci., 22, 271-277. 